\title{
THE IMPACT OF JOB DESIGN ON JOB COMMITMENT AND JOB SATISFACTION AMONG TEACHERS IN AL BATINAH GOVERNORATE NORTH, SULTANATE OF OMAN

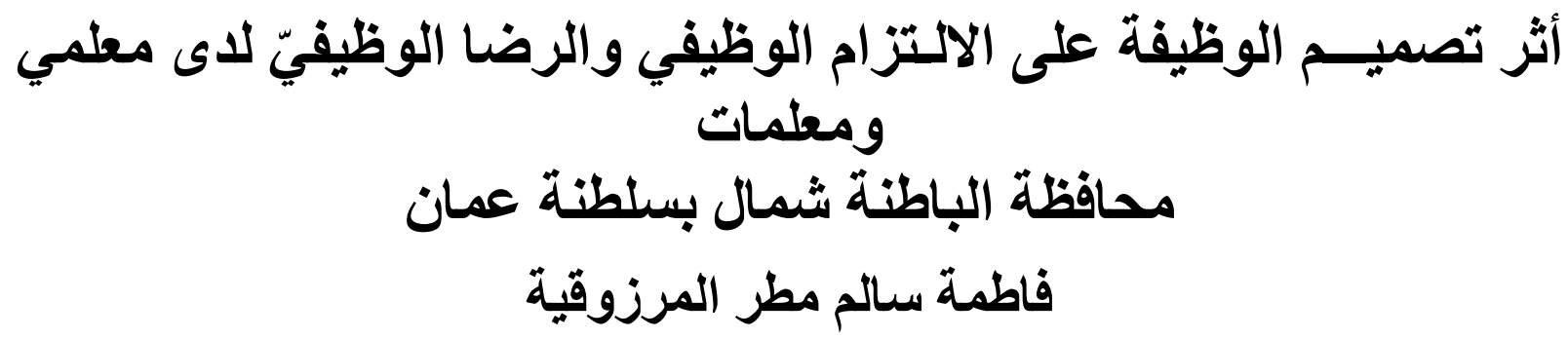

Fatema Salim Matar Marzuqi

Educational Supervisor, Ministry of Education, Sultanate of Oman, fatma.almarzogi@moe,om

\begin{abstract}
This quantitative study aimed at analyzing the factors underlying the functional design of the teachers of educational institutions in the Al Batinah Governorate, north of the Sultanate of Oman. The problem lies in the lack of adoption of modern trends and developments by those involved in job design, which has negatively affected organizational commitment and job satisfaction, and the obstacles to job satisfaction and organizational commitment are still many. Therefore, the study aimed to diagnose levels of job design, job satisfaction and job commitment. It also aimed to analyze the effect of job design on job satisfaction and organizational commitment of male and female teachers. The researcher used the descriptive and analytical approach, which is based on collecting data on job design and related elements and measuring the correlations between the variables of the independent and dependent study. A questionnaire was designed consisting of (45) phrases distributed in three axes. A stratified random sample of (300) male and female teachers was selected. The researcher used the descriptive analysis method and the multivariate analysis of variance. The results of the study showed that there is a statistically significant relationship between the job design factors and the factors of job satisfaction and organizational commitment of male and female teachers. The study recommended activating and practicing freedom of performance indicators by male and female teachers as a basic functional factor affecting organizational satisfaction and commitment. The study also recommended the necessity of laying down correct foundations for the promotions system to enhance satisfaction.
\end{abstract}

Keywords: job design, job satisfaction, organizational commitment.

\section{الملخص}

هدفت هذه الدر اسة الكمية إلى تحليل العو امل الكامنة للتصميم الوظيفي لدى معلمي ومعلمات المؤسسات التعليمية التابعة لمحافظة الباطنة شمال بسلطنة عمان. وتكمن المشكلة في عدم الأخذ بالتوجهات

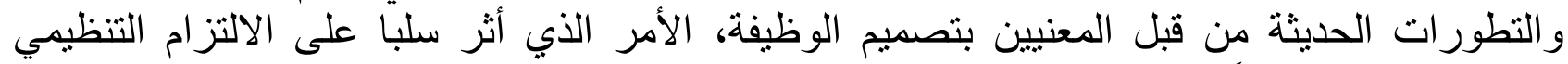

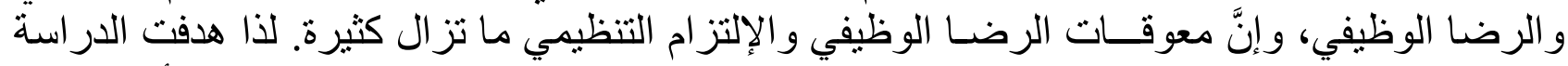
تشخيص مستويات تصميم الوظيفة والرضا الوظيفي والالتز ام الوظيفي، كما هدفت إلى تلى تحليل أثر تصميح

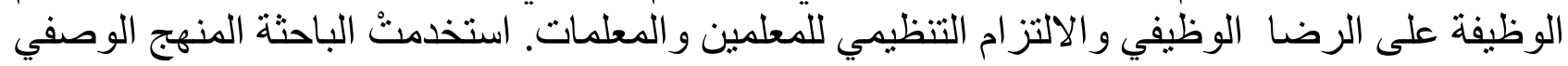
التحليلي، الذي يقوم على جمع البيانات عن تصميم الوظيفة، وما برتبط بها من عناصر، وقياس 
الارتباطات بين متغير ات الدراسة المستقلة و التابعة. تم تصميم استبانة تكونت من (45) عبارة توز عت في ثناثة محاور. وتم اختيار عينة عشوائية طبقية مكونة من (300) معلم ومعلمة. استخدمت الباحثة

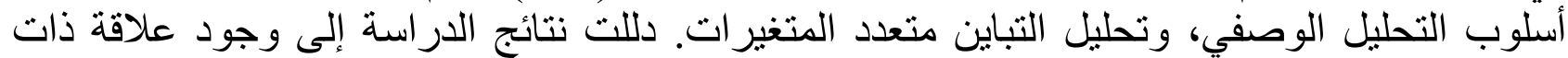

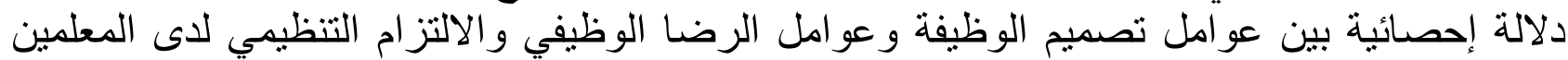

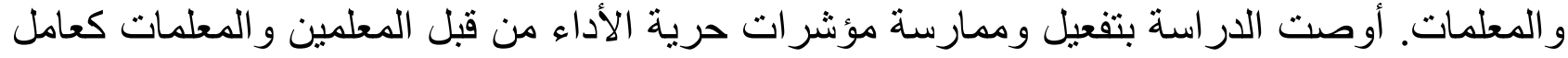

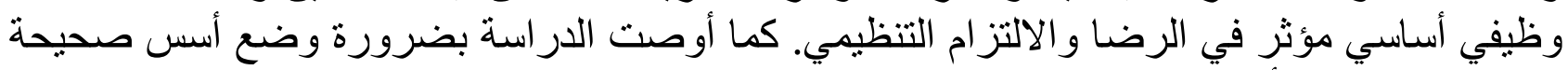

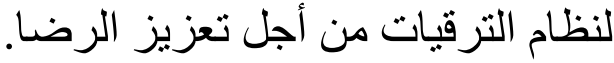
كلمات مفتاحية: تصميم الوظيفة، الرضا الوظيفي، الالتز ام التظيمي.

\section{المقدمة:}

يعتبر التصميم الجيد للوظائف هو الأساس الأول لتصميم الوظائف، وإعداد الهيكلة الوظيفية لأي وظيفة. ويتم ذلك من خلال مجموعة من العناصر التي تحدد كل الثروط و الواجبات و المهام

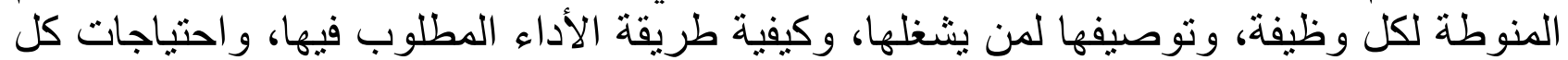
و ظليفة داخل كل مؤسسة تعليمية. ويعتبر أسلوب الإثراء الوظيفي من الأساليب الحديثة؛ المستخدمة في إعادة تصميم الوظائف في العصر الحديث؛؛ وذلك بهدف زيفة زئه المهام والأنشطة التربوية. وتعتبر وظيفة المعلم هي أم المهن التي تحتاج إلى إعادة النظر في تصميم الوظيفة؛ لكي تو اكب التطورات التربوية المعاصرة. و على الرغم من الجهود الي تبذلّها وزارة التربية و التعليم في تئي

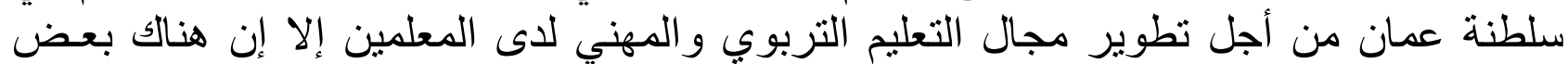

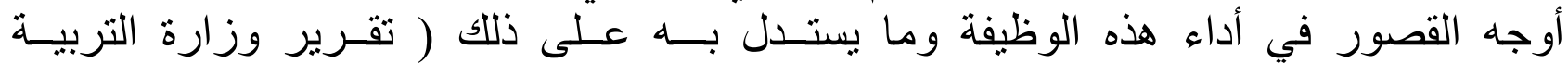

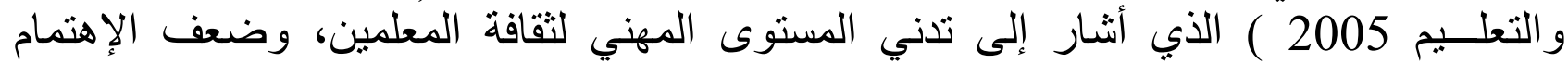
بالمعلمين ذوي الخبرة، وحاجة المدارس إلى وجود نظام تدريبي مستمر.

إن إعادة تصميم الوظيفة، يؤدي إلى نتائج مشجعة منها تخفيض معدل دوران العمل ومعدلات

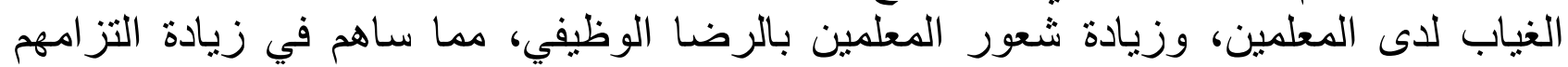

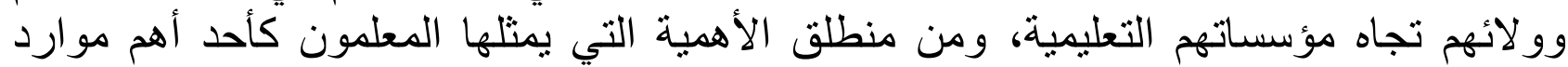
المؤسسة التعليمية؛ فإن تكوين قوة عمل قادرة على العمل ور اغبة فيه وتتميتهم يعد هدفا جو هريا تسعى إلى تحقيقه الإدارة المسؤولة عن المعلمين في المؤسسات التعليمية، و أيا كان مستوى التهون الكفاءة التي تتم فيها عملية اختيار وتعين المعلمين وما يرتبط بها من سياسات تتعلق بتكوين قوة العمل

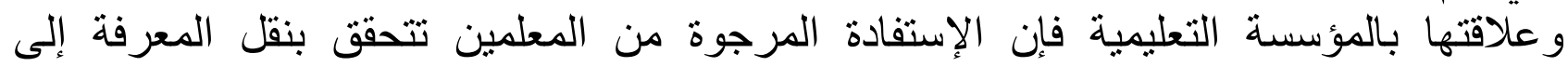

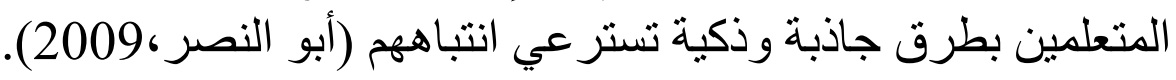

تعتبر المعرفة من أهم العوامل الأساسية التي تساهم في عملية تغير أفكار المجتمع، وتبني حضارة

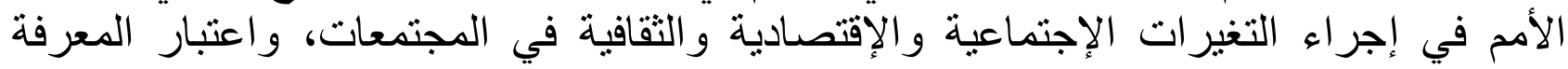
النقطة الَّوهرية في عصر المعلومات؛ فقد حثت الكثير من الدراسات الجديدة إلى تطوير النظام التعليمي من الداخل للحصول على نظام يو اكب التطور الذي نعيش فيه من خلال إعادة تصميم الوظيفة (الصالح، 2005، ومدبولي، الصني، 2007). و هنالك العديد من المشرو عات التربوية التي أدخلت في الحقل التربوي بهدف تطوير الأداء المهني 


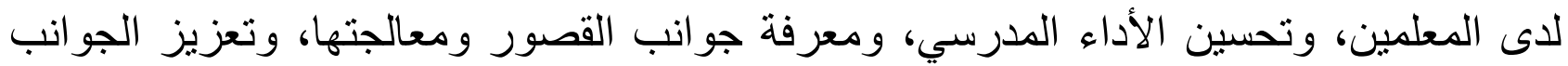

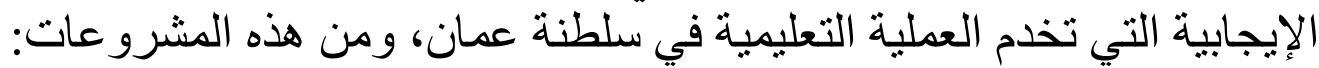

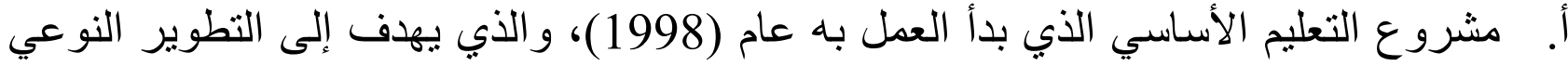
لمدخلات و عمليات ومخرجات العملية التعليمية (وزارة التربية و التعليم، دليل عمل مدارس التيل التعليم

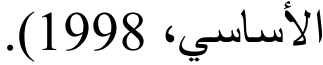

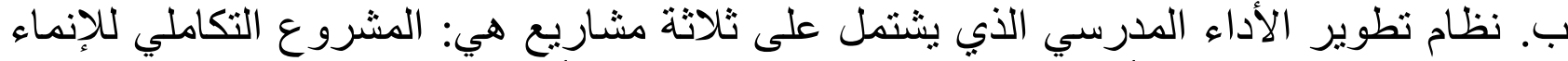

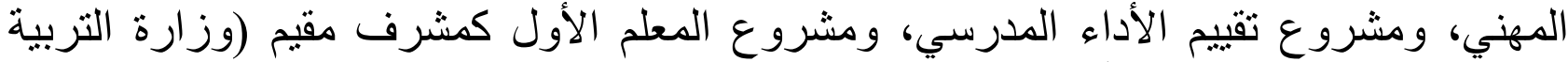
و التعليم، دليل نظام تطوير الأداء المدرسي، 2006).

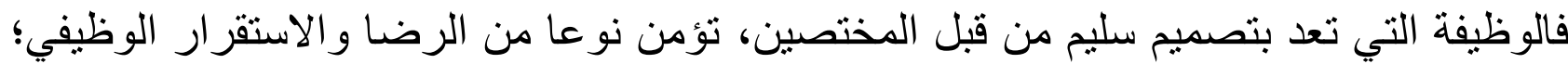

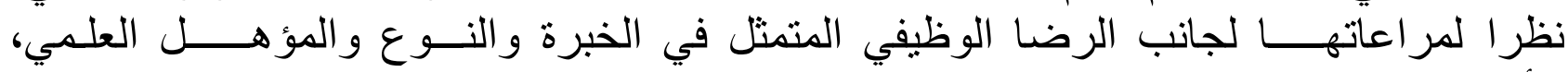

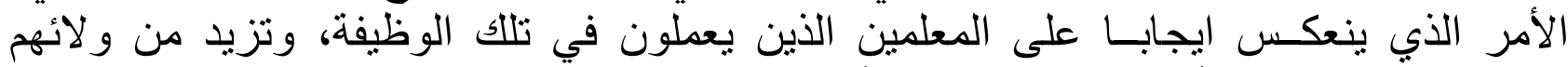
لمؤسساتهم التعليمية و أدائهم لمهامهم بشكل أفضل الفين.

مشكلة الدراسة

يعتبر تصميم الوظيفة عاملا من عوامل الرضا الوظيفي، والالتزام التنظيمي، وحلا لكثير من التئي

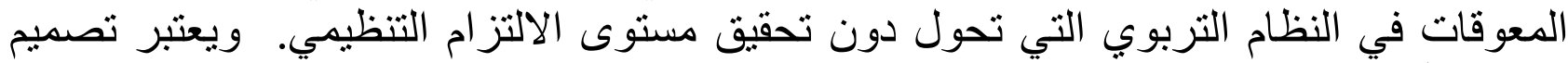

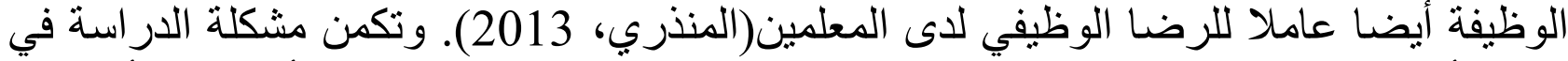
عدم الأخذ بالتوجهات والتطورات الحديثة من قبل المعنيين بتصميم الوظيفة الأمر الذي أنثر سلبا

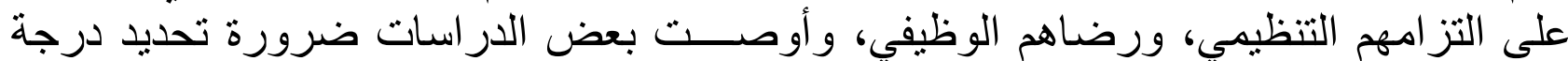

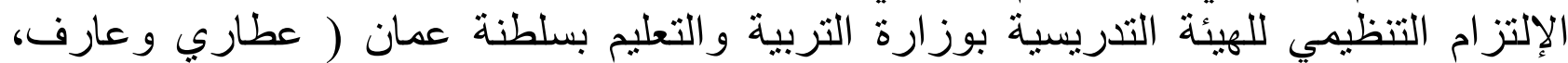

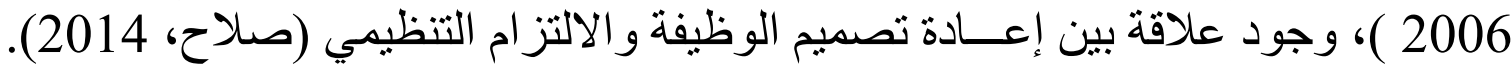
وبالرغم من الأنظمة التربوية التي اتخذتها وزارة التربية والتعليم بسلطنة عمان بهدف تحسين

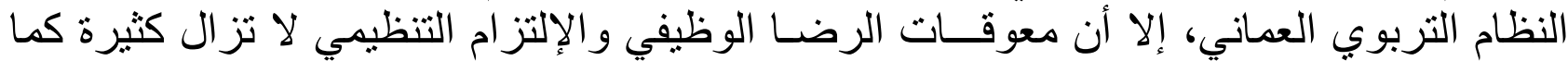

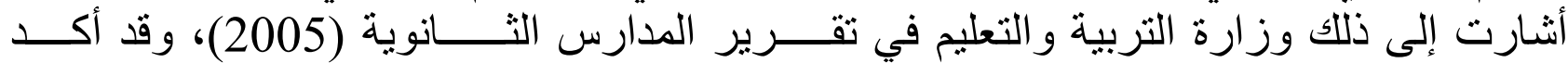

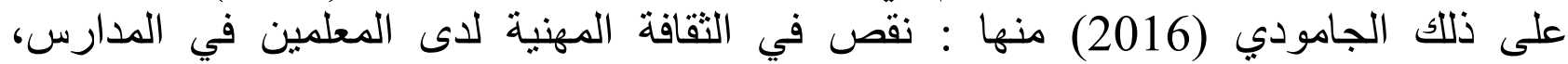

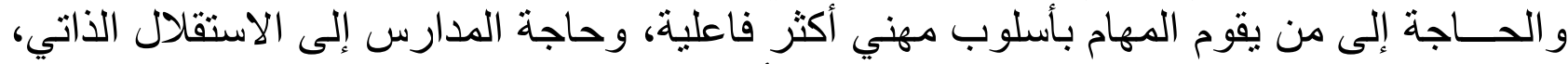

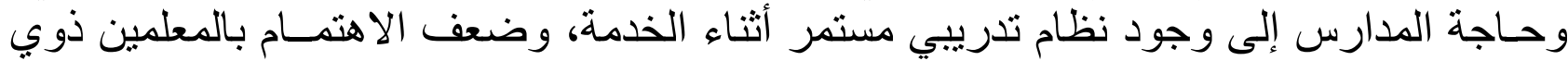

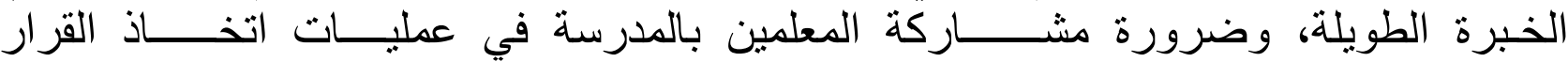
وصياغة الــــرؤى المستقلية.

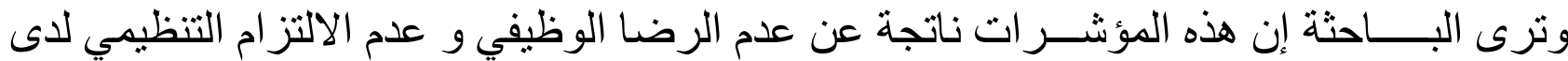

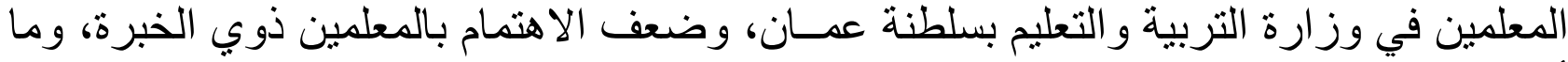

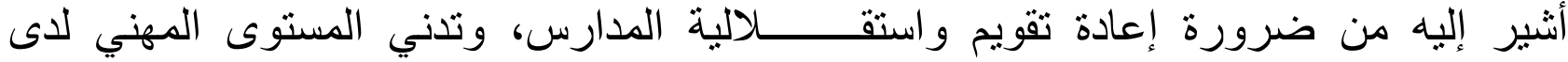

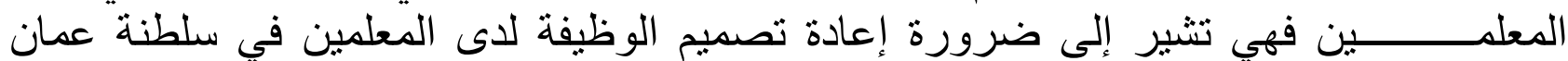

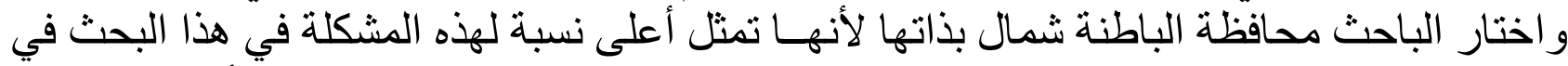

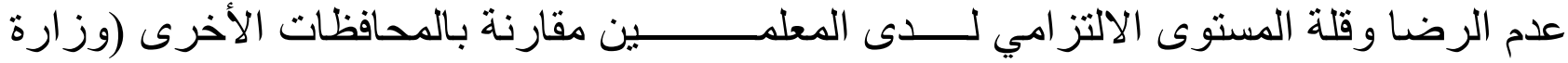

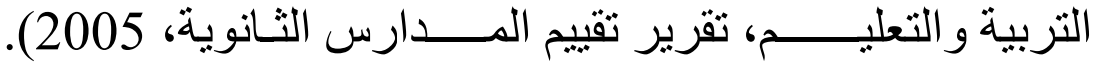




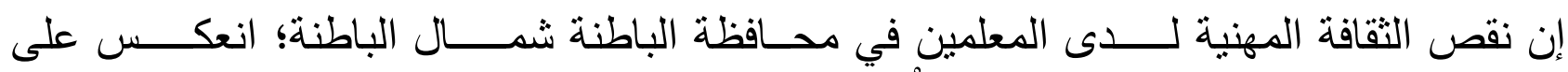

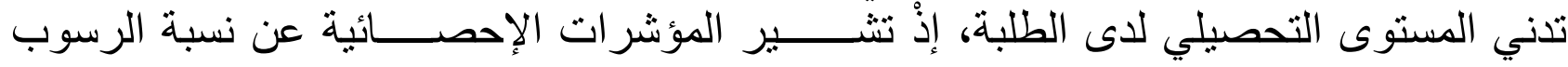

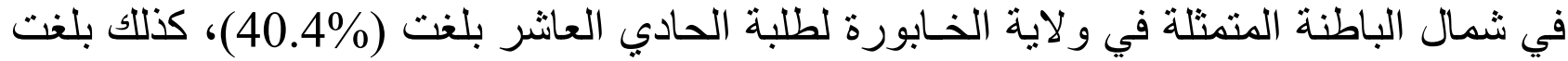

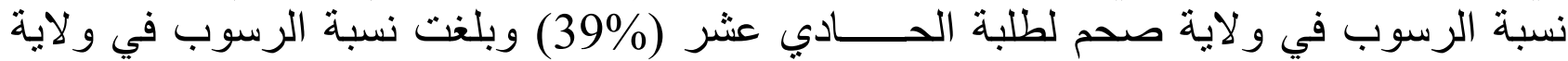

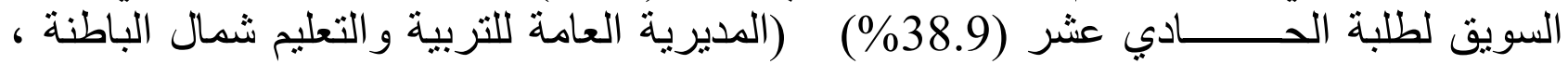
. 2014

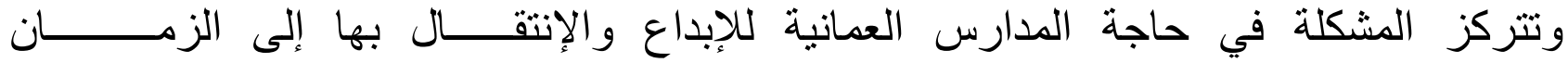

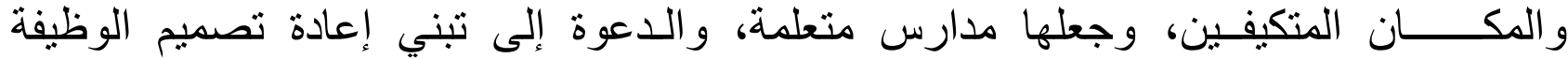

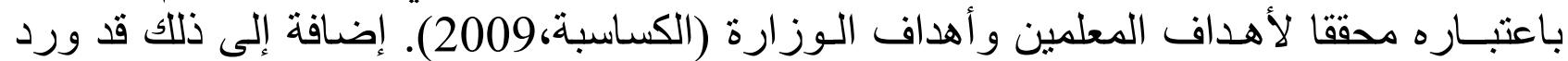

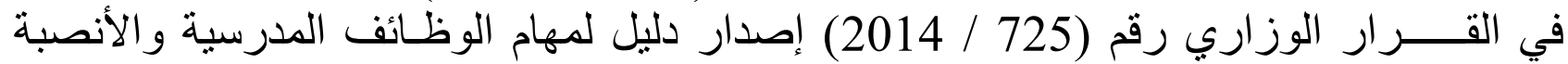
المعتمدة لها (وزارة التربية والتعليم، 2014). وانطلاقا من هذه التفاصيل فقد نشكلت مشكلة

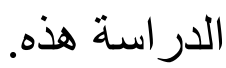

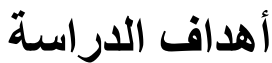

أو لا: تشخيص مستويات تصميم الوظيفة والرضا الوظيفي والالتزام الوظيفي.

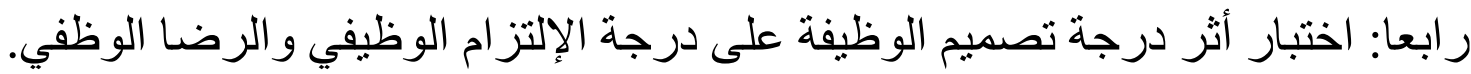

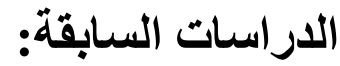

اطلعت الباحثة على عدد من الرسائل الجامعية والكتب و المجلات و الدوريات، و البحوث المتعلقة

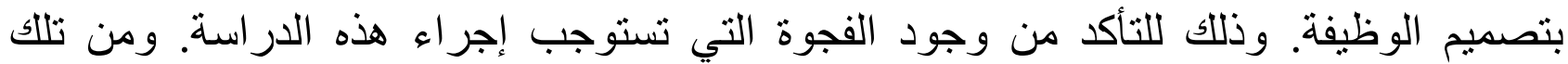

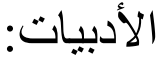

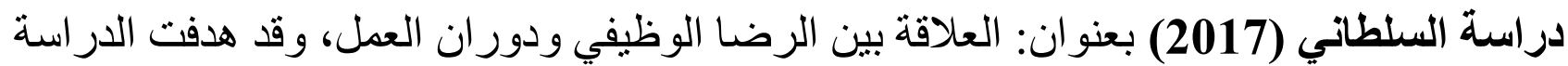

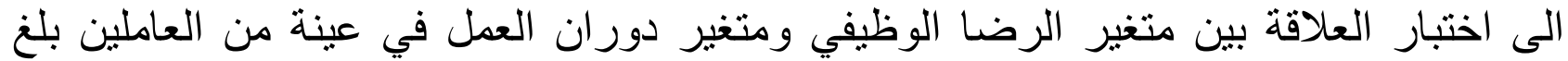

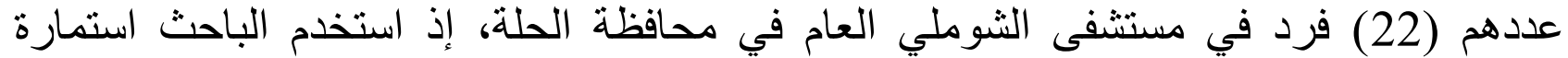

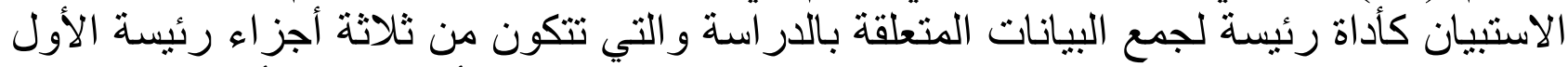

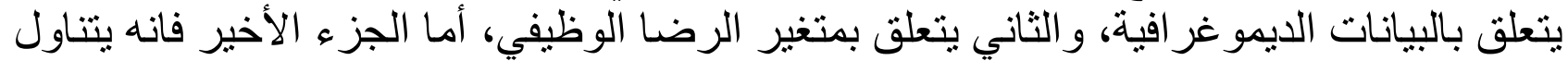

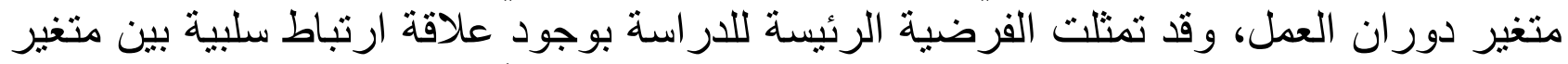

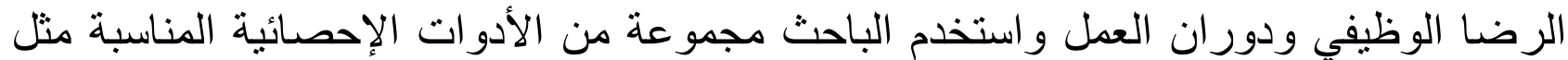

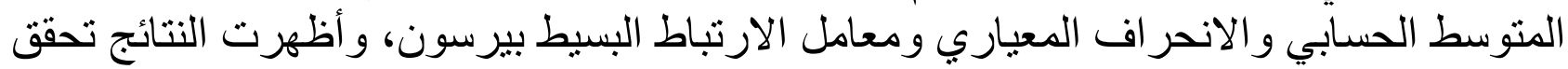

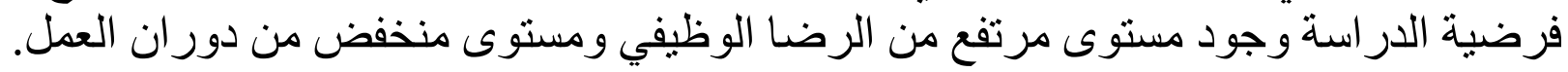

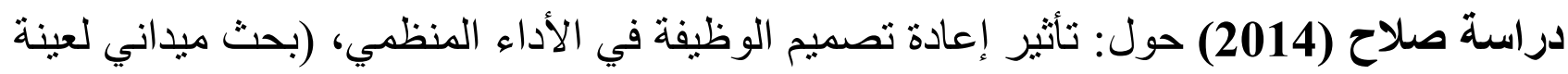

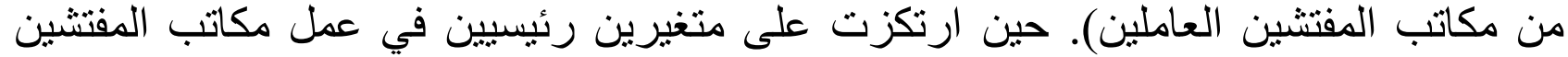

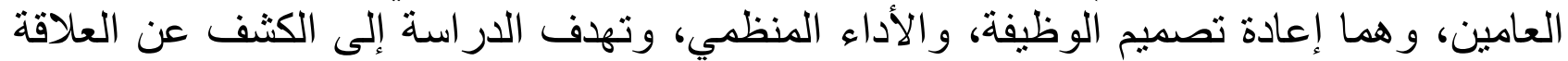

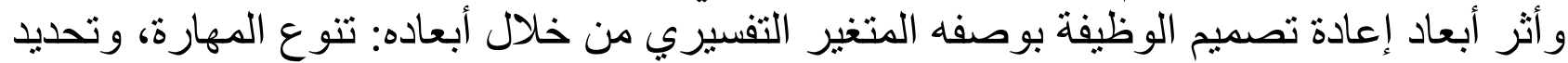

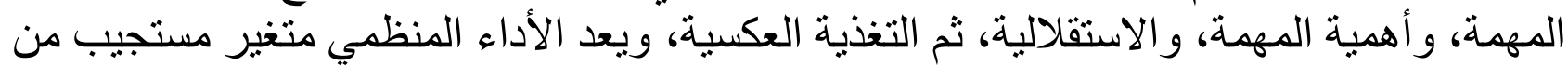

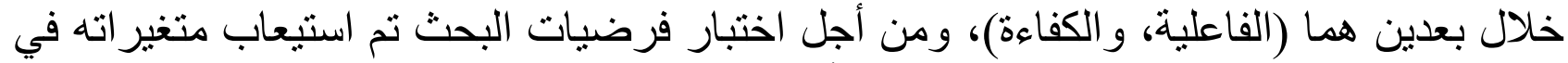

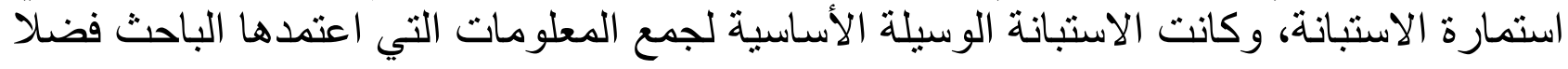




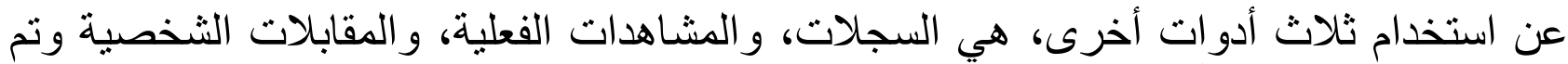

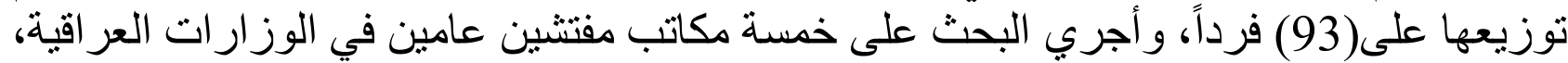

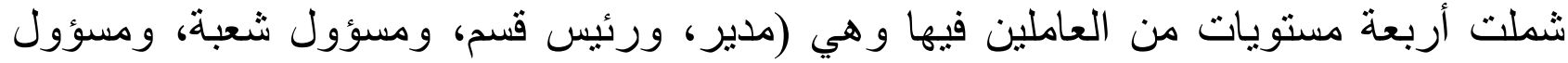

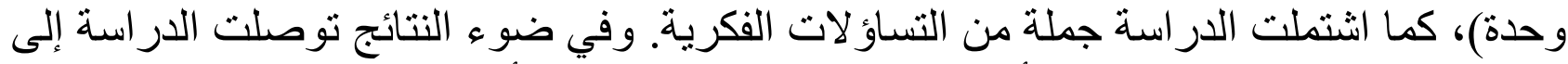

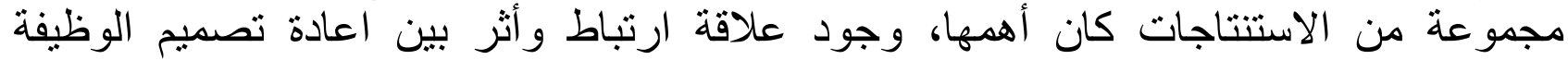

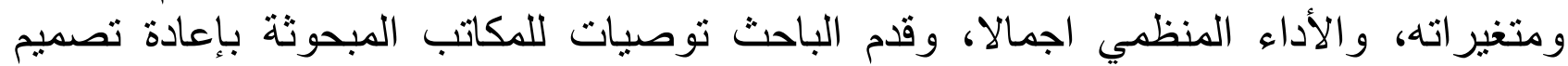

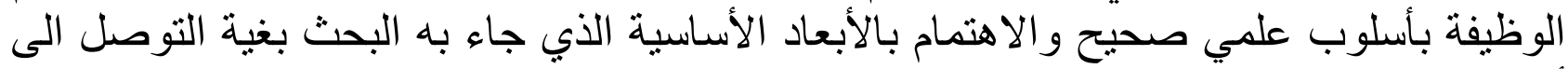
أداء منظمي جيد.

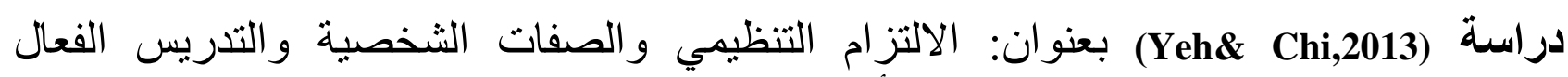

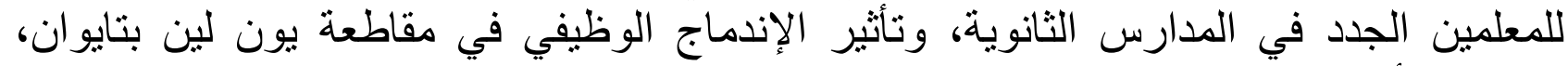

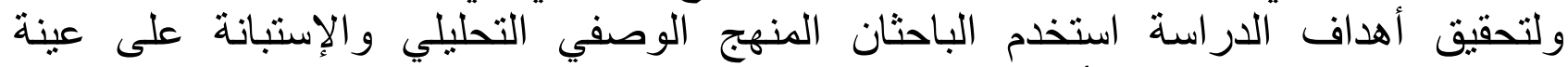

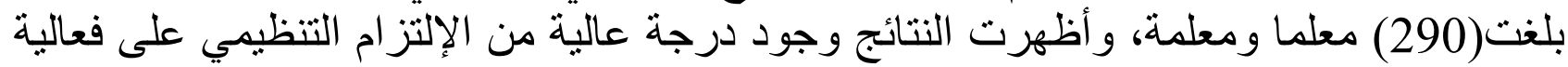

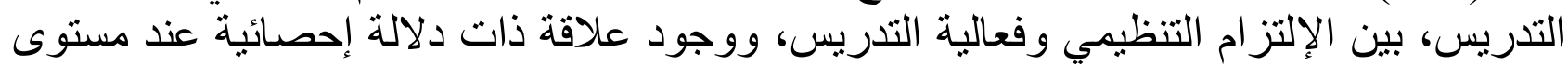

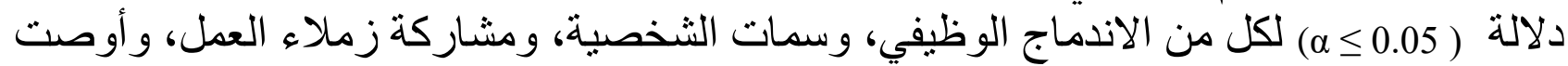

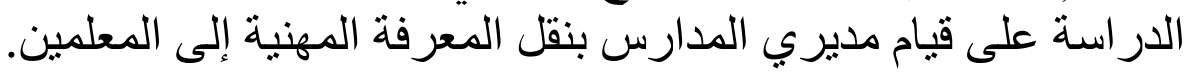

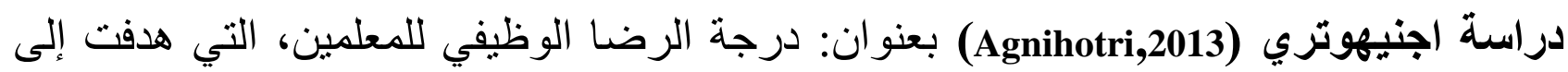

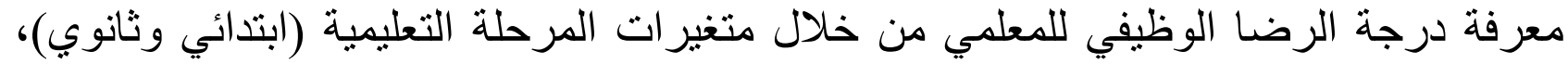

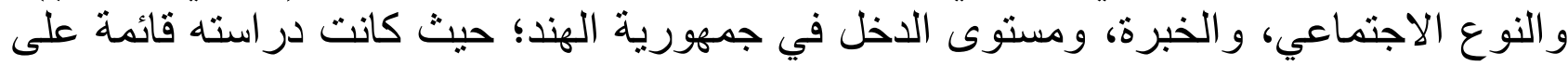

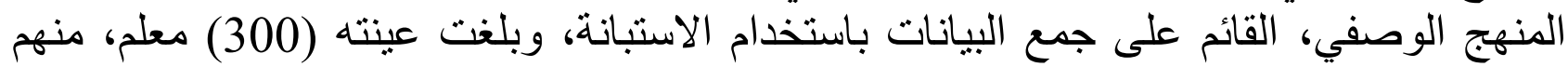

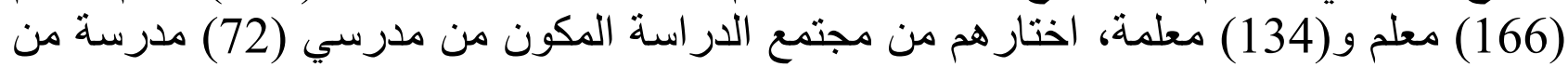

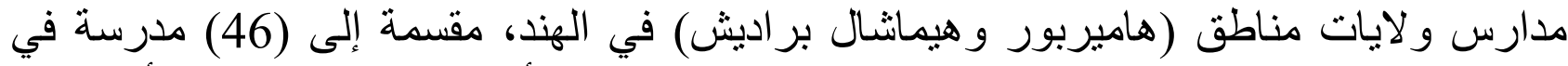

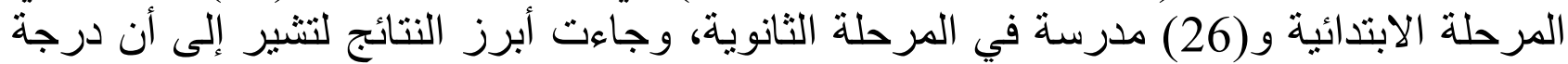

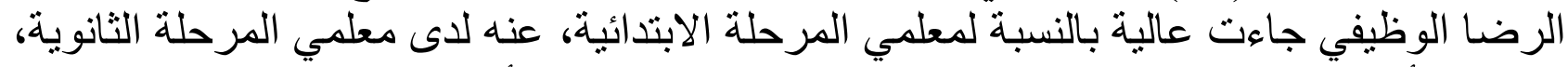

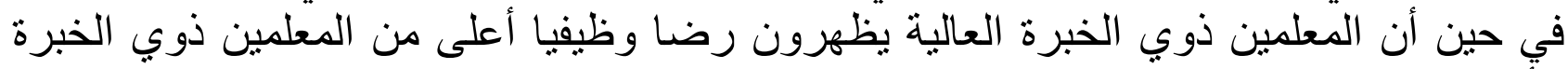

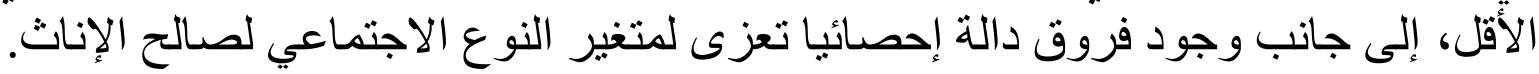

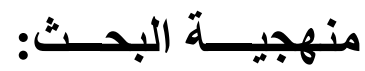

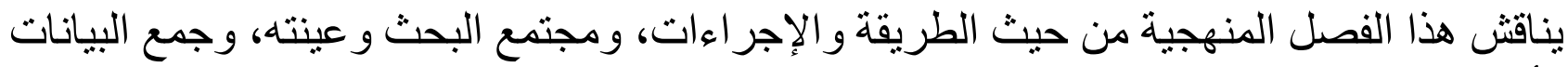

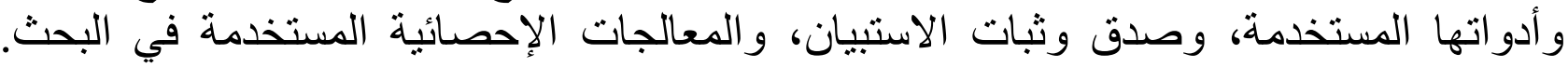

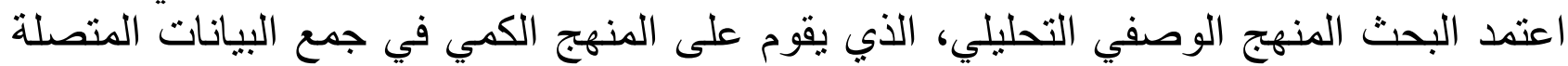

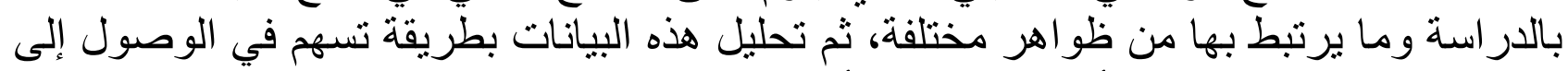

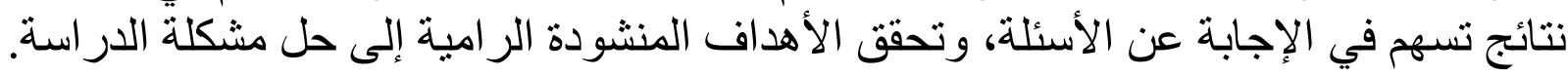

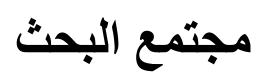

يتمثل حجم المجتمع في مجموع أعداد المعلمين والمعلمات على مختلف مستوياتهم الوظيفية

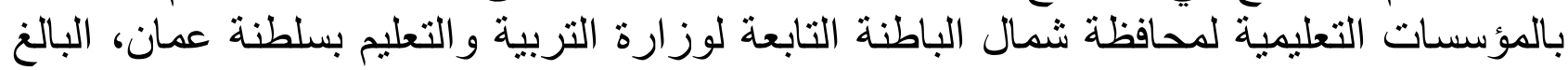
عددهم (10174) معلم ومعلمة (وزارة التربية و التعليم، 2016). 
أعتمد الباحث على عينة عثوائية ممثلة لمجتمع الدر اسة، بحيث تعكس أثر المتغيرات الثخصية

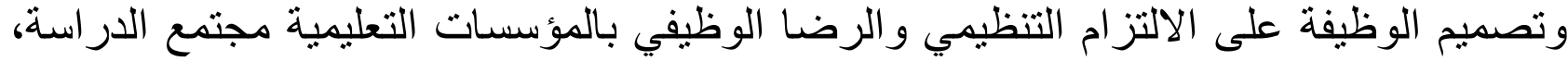

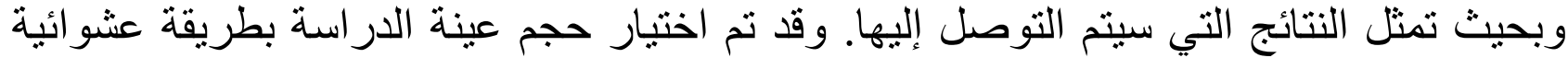
من المرجع (2008 Geoffrey E.) حيث بلغ حجم العينة (300) مفردة، موزعة الته على محافظة شمال الباطنة.

أداة البحث استبانة الدر اسة الميدانية: قامت الباحثة بإعداد الاستبانة في ضوء الاستفادة من الدراسات السابقة

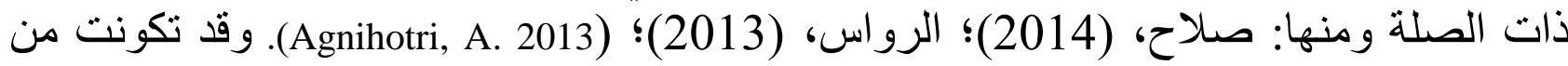

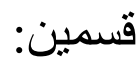
القسم الأول: البيانات الشخصية لأفراد عينة البحث تضمنت متغيرات النوع والمؤهل العلمي

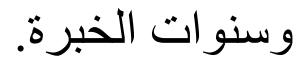

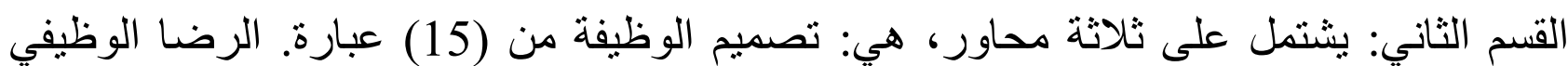

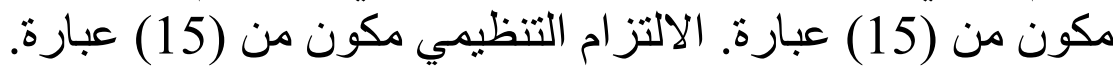

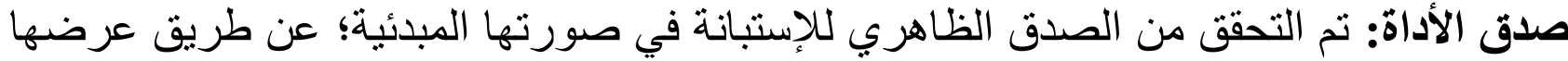

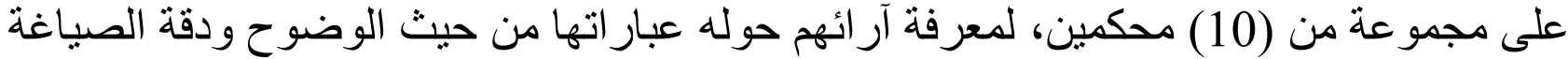

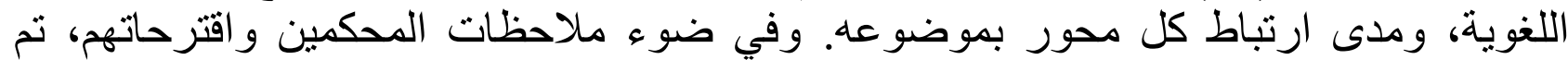
التعديل و أصبحت الاستبانة جاهزة في صورن التها النهائية. ثبات الأداة: يشير الثبات إلى قدرة الأداة على إعطاء نفس النتائج، إذا نم تكرار القياس على نفس

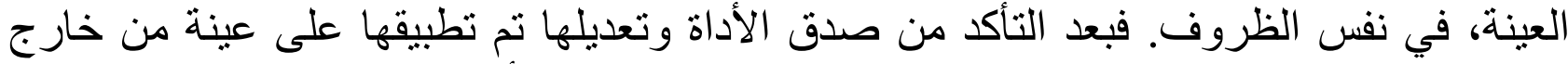

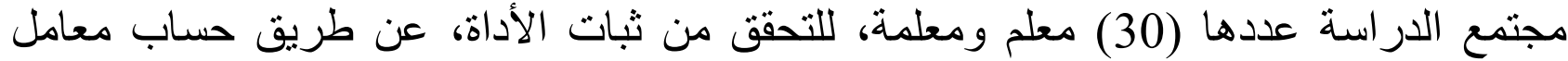

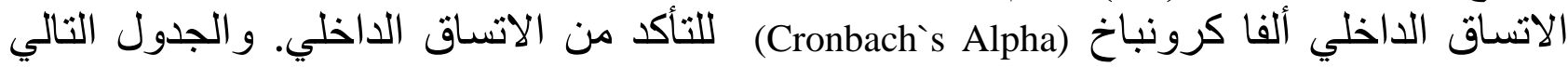
يوضح معاملات الثبات.

\begin{tabular}{|c|c|}
\hline معامل الفا كرونباخ & المجالات \\
\hline 0.73 & تصميم الوظيفة \\
\hline 0.87 & الرضا الوظيفي \\
\hline 0.78 & الالتز ام التنظيمي \\
\hline 0.89 & ثبات الاداة ككل \\
\hline
\end{tabular}

نلاحظ من الجدول أعلاه أن معاملات الثبات ثر اوحت بين 0.73 إلى 0.89 و هي معاملات مناسبة تدل على صلاحية الأداة للنطبيق.

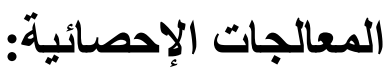
تم الاعتماد على برنامج الرزمة الإحصائية للعلوم الاجتماعية (SPSS) في ادخال بيانات البحث 
الميدانية وتحليلها باستخدام الأساليب الإحصائية الآتية:

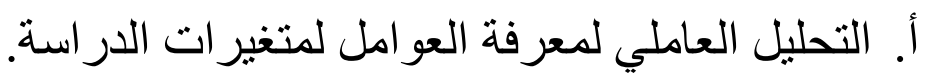

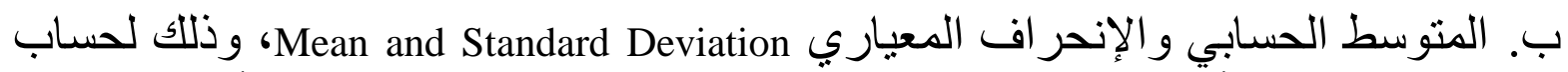

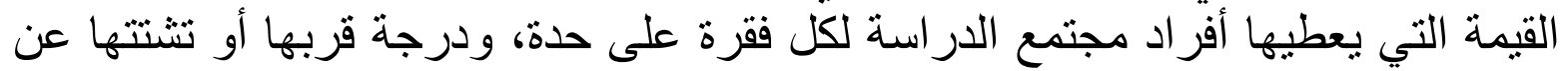

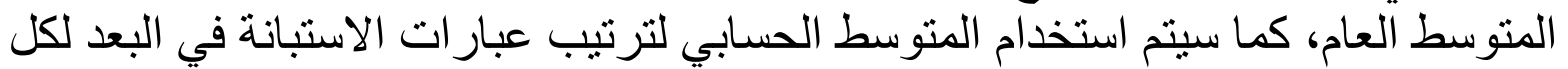
من محوري الأهمية ودرجة التطبيق.

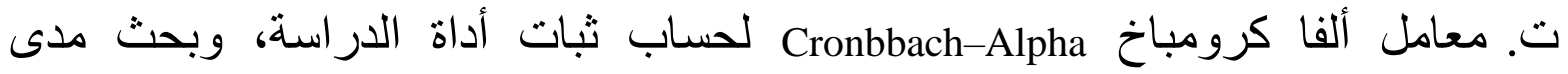
الاعتماد على نتائج الدر اسة الميدانية في تقييم النتائج.

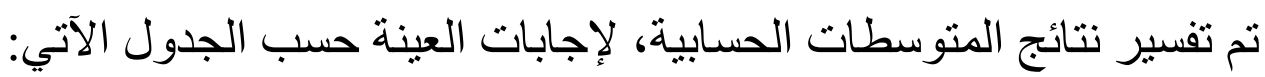
الجدول (2) تفسير المتوسطات الحسابية

\begin{tabular}{|c|c|}
\hline التقدير & المدى \\
\hline ضعيف جداً & من 1 إلى 1.79 \\
\hline ضعيف & 1.80 إلى 2.59 \\
\hline متوسط & 2.60 إلى 3.39 \\
\hline عالي & 3.40 إلى 4.19 \\
\hline عالي جداً & 4.20 إلى 5.00 \\
\hline
\end{tabular}

نتائج الاراسة:

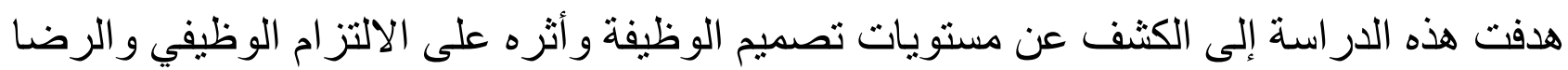

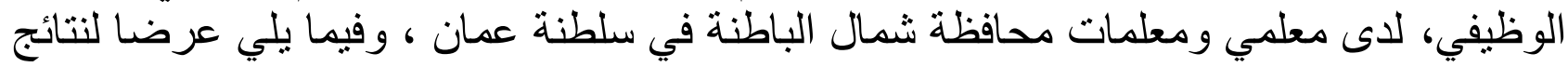
الدر اسة:

\section{مستويات تصميم الوظيفة والرضا الوظيفي والالتزام الوظيفيي:}

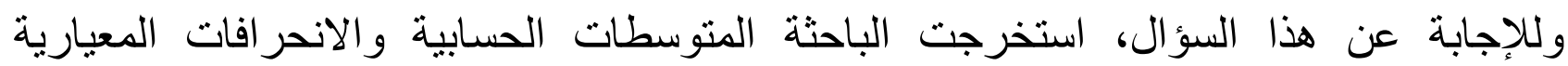

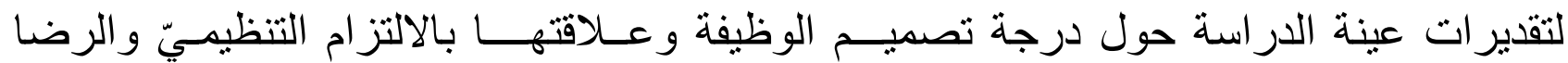

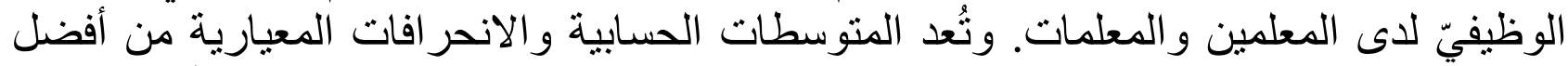

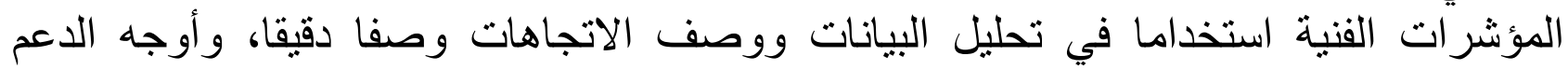
للظواهر التي تتبع التوزيع الطبيعي الاعتدالي، على الني النحو التالي:

درجة تصميم الوظيفة

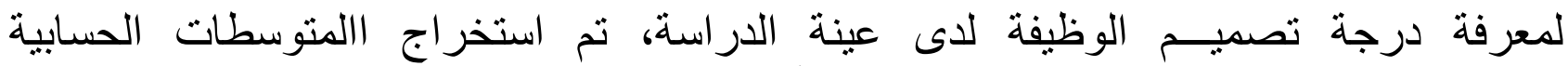

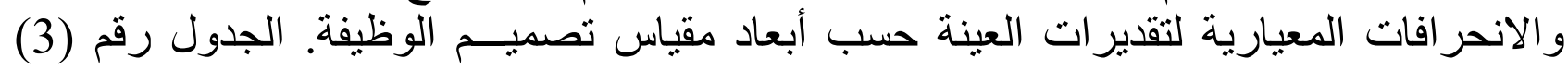
يوضتح نتائج السؤ ال. 
الجدول (3) المتوسطات الحسابية و الانحر افات المعيارية لأبعاد مقياس تصميـــم الوظيفة، مرتبة تنتاز ليا

\begin{tabular}{|c|c|c|c|c|c|}
\hline التقرجير & المعياري & الحستوسي & الأبعاد & 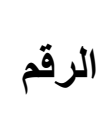 & الرتبة \\
\hline 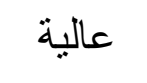 & 0.63 & 3.72 & بُعد وضوح المهام & 2 & 1 \\
\hline متوسطة & 0.82 & 3.28 & بُعد حرية الأداء & 1 & 2 \\
\hline منو سطة & 0.78 & 3.18 & بُعد أسس الترقيات & 3 & 3 \\
\hline متوسطة & 0.42 & 3.39 & مقياس تصميم الوظيفة ككل & & \\
\hline
\end{tabular}

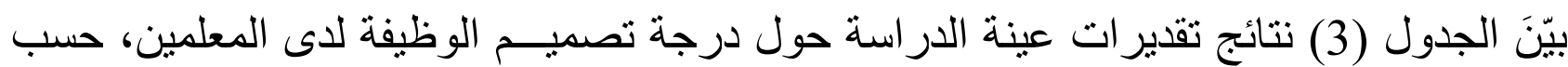

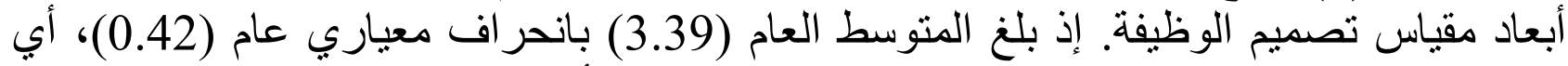

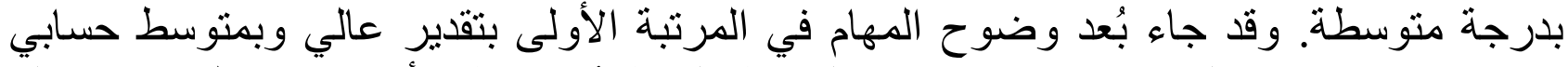

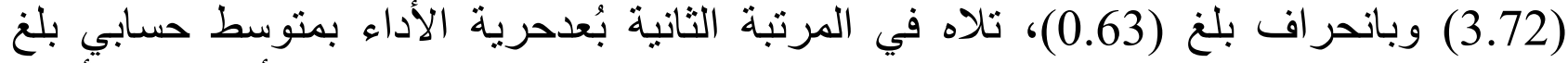

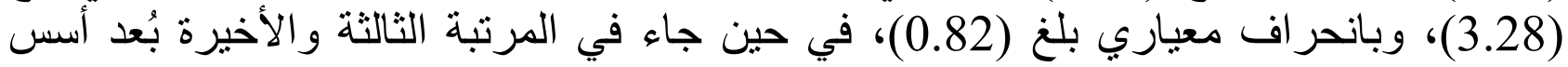

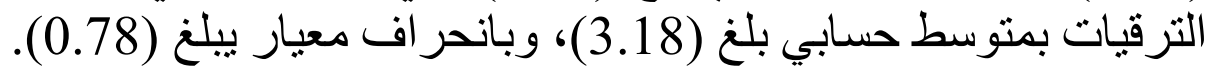

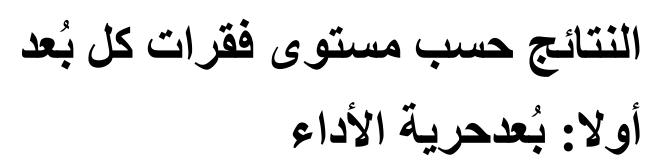

الجدول (4) المتوسطات الحسابية و الانحر افات المعيارية لفقر ات بُعد حرية الأداء، مرتبة تنازليا

\begin{tabular}{|c|c|c|c|c|c|}
\hline 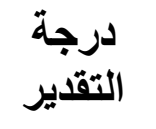 & 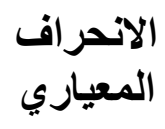 & 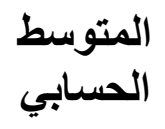 & 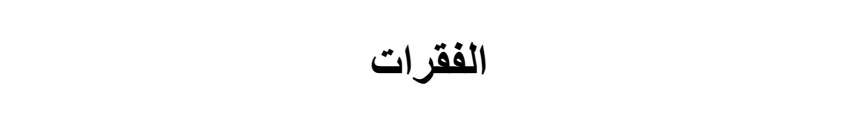 & 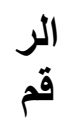 & 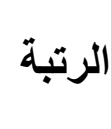 \\
\hline عالية & 0.97 & 3.60 & توفر الوظيفة القدرة على اتخاذا القرارات لإتمـام عمل & 10 & 1 \\
\hline متوسطة & 1.11 & 3.39 & توفر الوظيفة فرص للتطوير المهني المستمر & 11 & 2 \\
\hline متوسطة & 1.12 & 3.28 & تشجع الوظيفة المعلمين على الإبداع و التجديد في أداء & 7 & 3 \\
\hline متوسطة & 1.07 & 3.26 & تشجع الوظيفة المعلمين على اتخاذ القرارتلاتمام العمل & 13 & 4 \\
\hline 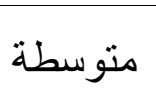 & 1.10 & 3.21 & تمثل الوظيفة أهمية كبيرة لعدد كبير من الأفر ادوتؤثر & 12 & 5 \\
\hline متوسطة & 1.06 & 3.12 & تقدم الوظيفة للمعلمين فرصة جديدة للإستقلالية في أداء & 8 & 6 \\
\hline متوسطة & 1.20 & 3.08 & تتطلب الوظيفـة التعـاون مــع الأفـر اد الأخـرين لإنجــاز & 14 & 7 \\
\hline
\end{tabular}




\begin{tabular}{|c|c|c|c|}
\hline & & & المهام التي تحتويها \\
\hline متوسطة & 0.82 & 3.28 & "المستوى العام لبعد حرية الأداء \\
\hline
\end{tabular}

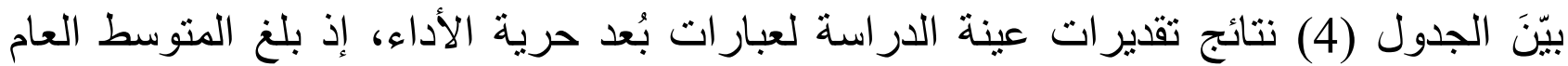

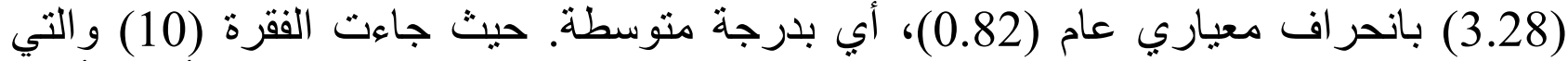

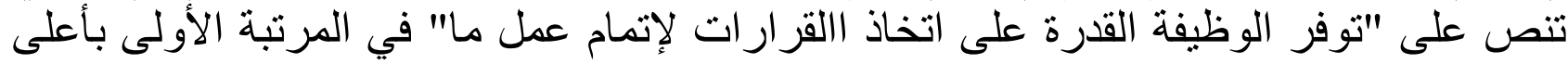

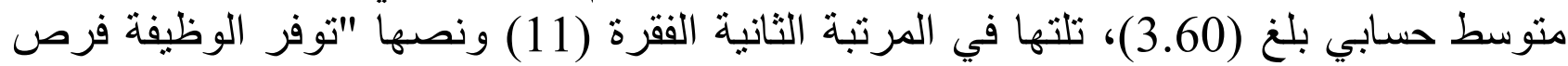

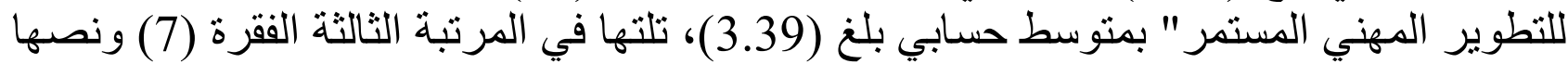

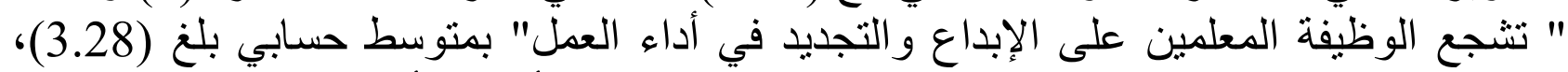

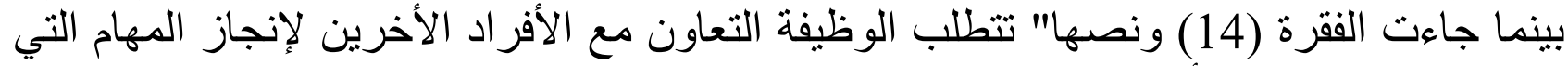
تحتويها" في المرتبة الأخيرة بمنوسط حسابي بلغ (14) (3.08).

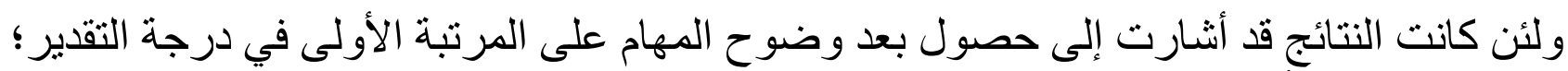

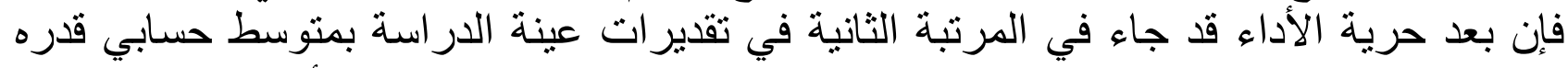

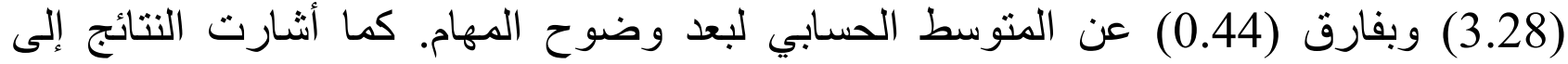

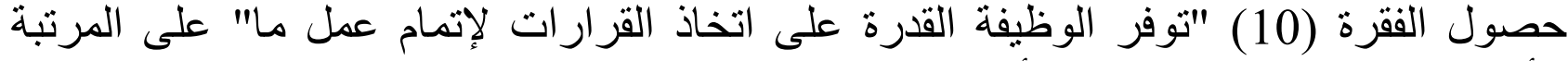

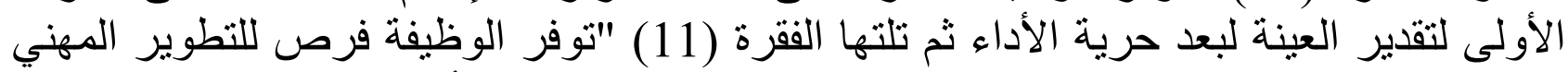

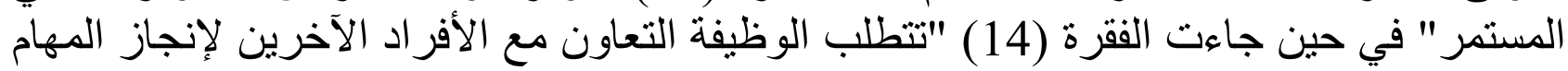
التي تحتويها".

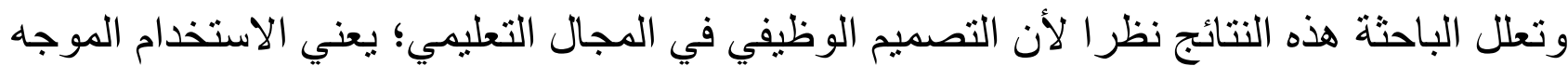

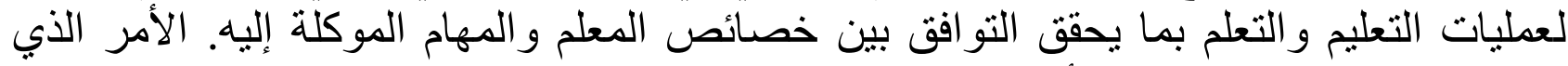

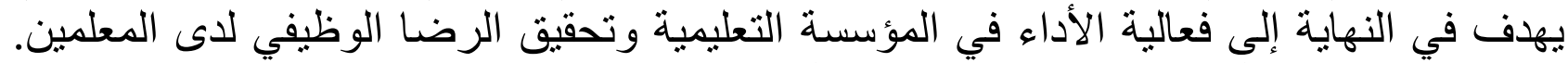

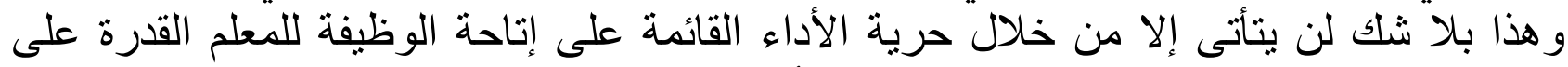

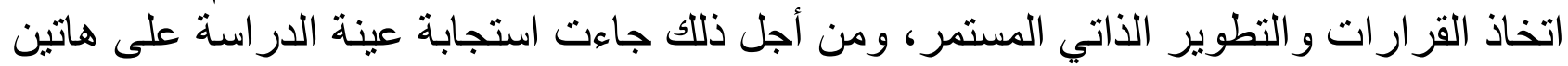

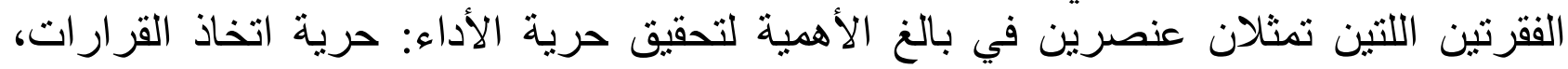
ونوفير الفرص الملائمة للنطوير الذاتي لاى المعلمين لكي يشعروا بتحمل مسؤولياتهم.

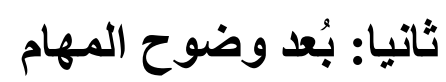
الجدول (5) المتوسطات الحسابية و الانحر افات المعيارية لفقر ات بُعد وضوح المهام، مرتبة تنازليا

\begin{tabular}{|c|c|c|c|c|c|}
\hline التقاير & 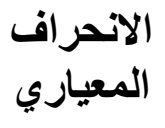 & 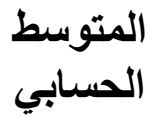 & 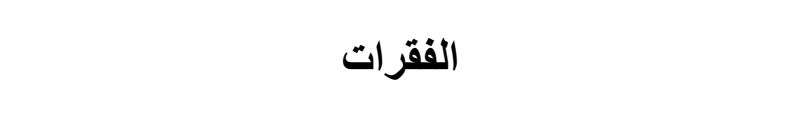 & 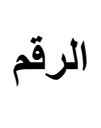 & 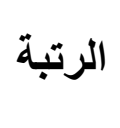 \\
\hline 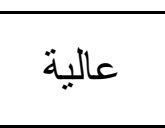 & 0.84 & 4.10 & تقأخرين الوظيفة للمعلمين العمل بصورة منعاونـة مـع & 9 & 1 \\
\hline عالية & 1.19 & 3.98 & وظيفتي. & 4 & 2 \\
\hline 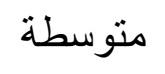 & 1.04 & 3.08 & أثشعر بوجود معايير عادلة في مهام وظيفتي & 3 & 3 \\
\hline
\end{tabular}




\section{عالية}

0.63

3.72

المستوى العام لبعد وضوح المهام

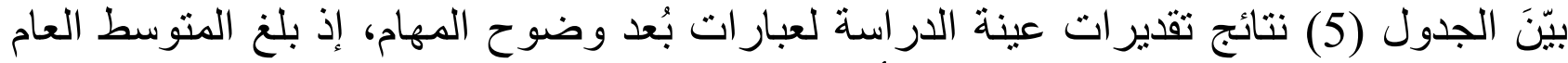

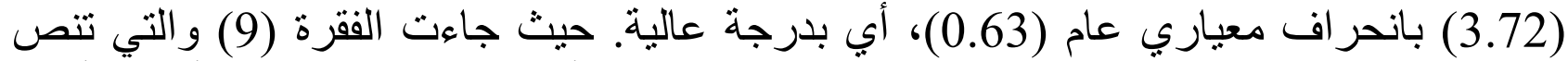

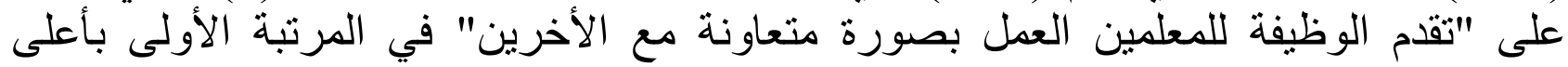

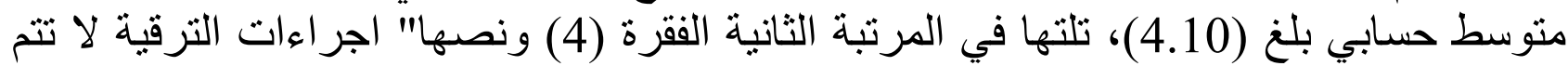

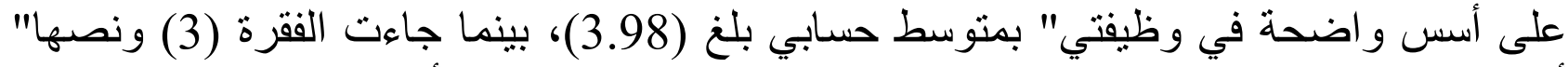

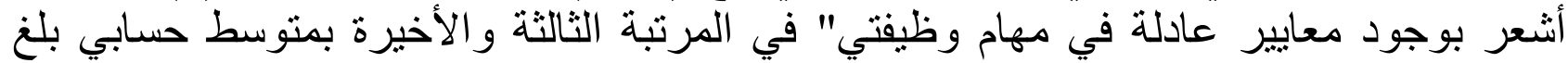

ثالثا: بُعد أسس الترقيات

الجدول (6) المتوسطات الحسابية والانحر افات المعيارية لفقر ات بُعد أسس الترقيات، مرتبة تناز ليا

\begin{tabular}{|c|c|c|c|c|c|}
\hline التقدجة & 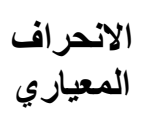 & 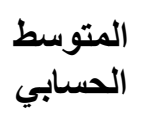 & 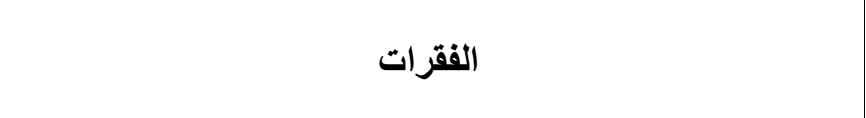 & 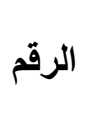 & الرتبة \\
\hline عالية & 1.06 & 3.53 & في اداء الثعر بتلبية حاجاتي الوظيفيـة وفق الفروقات الفرديـة & 5 & 1 \\
\hline متوسطة & 1.08 & 3.41 & تتميز الوظيفة بالرتابة في أداء المهام & 6 & 2 \\
\hline منوسطة & 1.15 & 3.24 & تخلو وظيفتي من تحفيز المعلمين المبدعين & 2 & 3 \\
\hline متوسطة & 1.30 & 2.53 & لم أطلع على المهام الوظيفة الخاصة بعملي. & 1 & 4 \\
\hline متوسطة & 0.78 & 3.18 & المستوى العام لبعد الترقيات & & \\
\hline
\end{tabular}

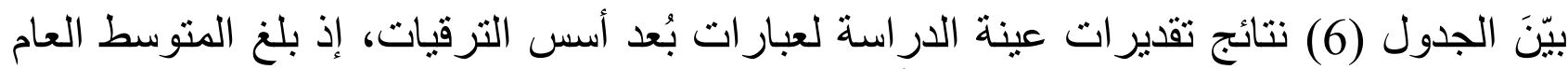

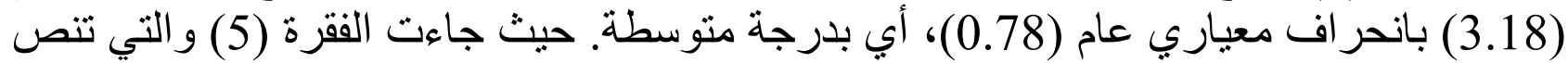

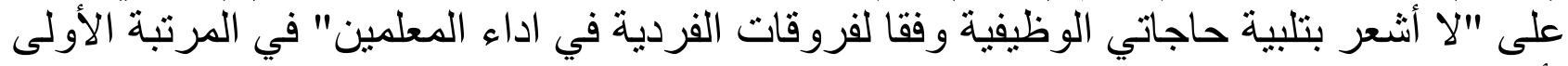

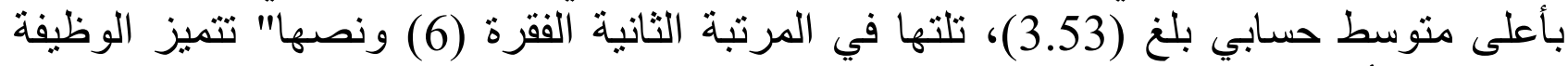

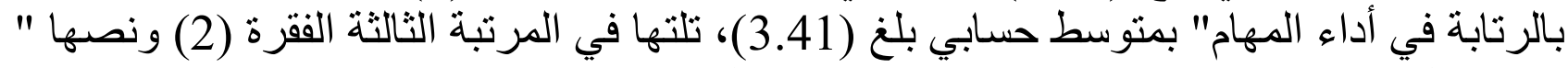

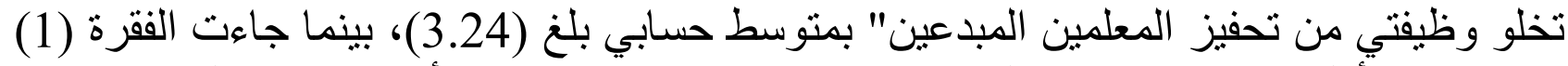

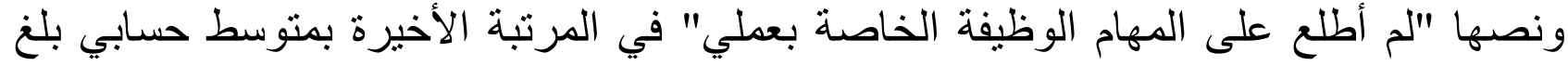

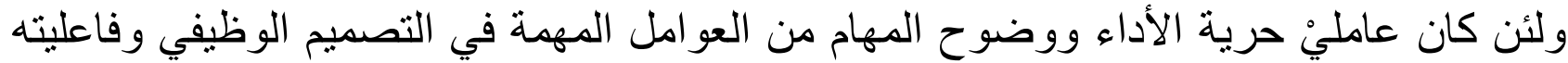

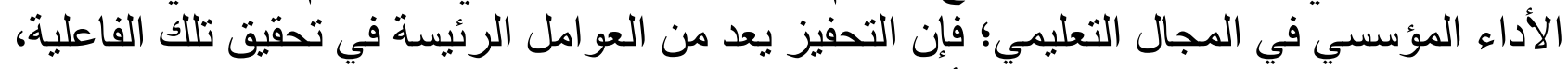

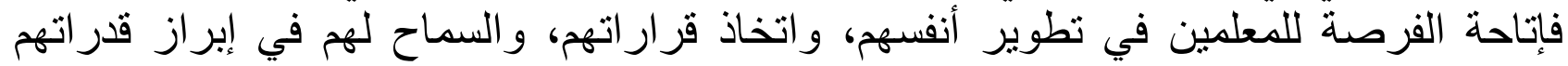

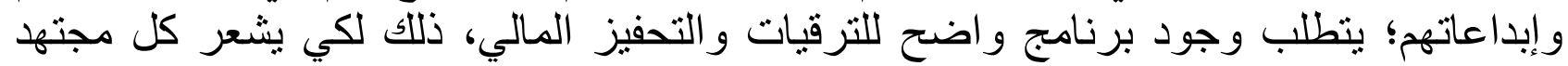
باجتهاده، وكل مجد بثمرة تميّزه و إبداعه.

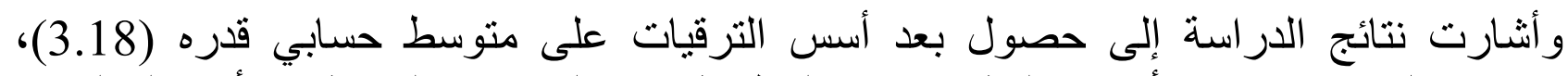

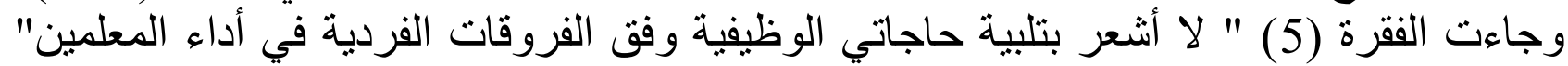

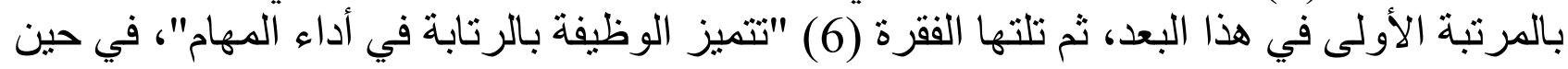


جاءت الفقرة (1) " لم أطلع على المهام الوظيفية الخاصة بعملي" في المرتبة الأخيرة لتقدير العينة.

وترجع الباحثة الأسباب لحصول الفقرة (5) على أعلى ترتيب في بعد أسس الترقيات نظرا لأن مهام المعلمين لا تفرق بين بعضهم البعض باستنتاء في اختلاف المستوى الوظيفي، أما على لئى

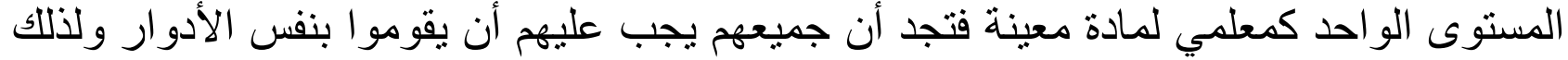

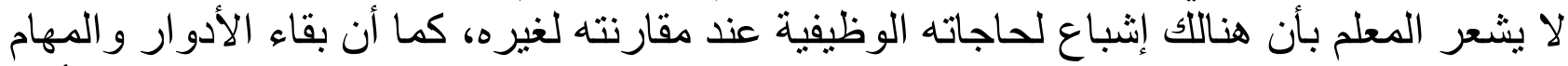
كما هي دون تجديد يؤدي إلى هذا الثعور، ويقود كذلك إلى شعور المعلمين بالرتابة في أداء أعمالهم، و هذا ما يفسر كذانلك- حصول الفقرة (6) على المرنبة الثانية في هذا البعد. إضافة إلى ذلك فإن وجود أساس للترفيات معتمدا على سنوات الخبرة كأساس في التحفيز دون النظر إلى الفروقات الفردية في أداء المعلمين، ودون التمبيز بين المبدعين منهم و المقلدين، ودون ودين

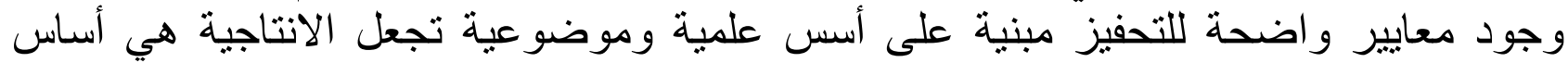
الفعلي للترقيات؛ فإن جميع ذلك يسبب ضعفا مستقبليا في الأداء الوظيفي للمعلمين. ثانيا: درجة الرضالوظيفي لمعرفة درجة الرضا الوظيفي لدى أفراد العينة؛ استخرج الباحث المتوسطات الحسابية و الانحر افات المعيارية لتقديرات عينة الدراسة حسب أبعاد مقياس الرضا الوظيفي، وفقا للجدول (7) (7) الآتي:

الجدول (7) المتوسطات الحسابية و الانحر افات المعيارية لأبعاد مقياس الرضا الوظيفي، مرتبة تنازليا

\begin{tabular}{|c|c|c|c|c|c|}
\hline درجة الرضا & الالمعراف & المتوسطي & الأبعاد & الرقم & الرتبة \\
\hline عالية & 0.70 & 3.96 & بُعد العدالة & 3 & 1 \\
\hline متوسطة & 0.77 & 3.17 & بُعد التحفيز & 1 & 2 \\
\hline متوسطة & 0.81 & 2.81 & بُعد الانتماء & 2 & 3 \\
\hline متوسطة & 0.65 & 3.31 & معدل الرضا الوظيفي & & \\
\hline
\end{tabular}

بيّنَ الجدول (7) نتائج تقديرات عينة الدراسة لعبارات درجة الرضا الوظيفي لدى المعلمي

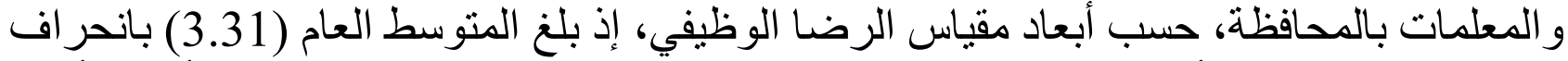

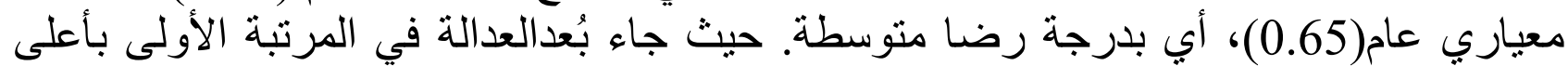
منوسط حسابي بلغ (3.96)، وبانحر اف معياري بلغ (0.70)، (0.17)، تلاه في المرنبة الثانية بُعد التحفيز

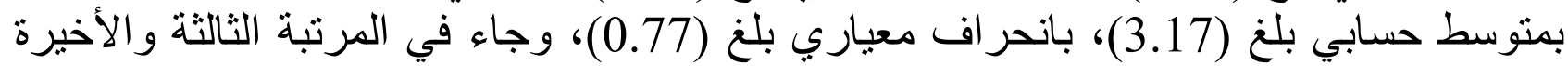


بُعد الانتماء بمتو سط حسابي بلغ (2.81)، وبانحر اف (0.81).

النتائج حسب مستوى فقرات كل بُعد

أولا: بُعدالتحفيز

الجدول (8) المتوسطات الحسابية و الانحر افات المعيارية لفقر اتبُعدالتحفيز ، مرتبة تنازليا

\begin{tabular}{|c|c|c|c|c|c|}
\hline الرضا & المعياري & 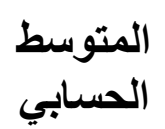 & 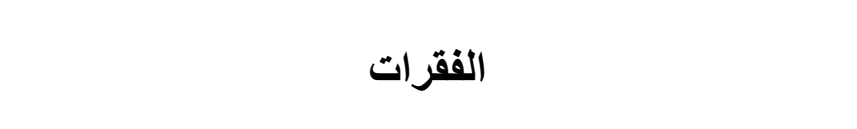 & 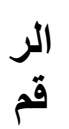 & الرتبة - الة \\
\hline متوسطة & 1.04 & 3.54 & لا لاع فرق بينة المعلم المقصر و المعلم المبدع في التحفيز & 2 & 1 \\
\hline متوسطة & 0.98 & 3.36 & أحب كثير ا العمل الذي أؤديه. & 4 & 2 \\
\hline متوسطة & 1.09 & 3.23 & أنثعر بأهمية العمل الذي أؤديه. & 5 & 3 \\
\hline متوسطة & 1.20 & 2.90 & لا توجد حو افز مادية تجعل المعلم يجتهر في عمله. & 3 & 4 \\
\hline متوسطة & 1.05 & 2.82 & هناك احتر ام من أولباء الأمور و الطلبة لوظيفتى. & 9 & 5 \\
\hline متوسطة & 0.77 & 3.17 & المستوى العام & & \\
\hline
\end{tabular}

يبين الجدول (8) نتائج تقدير ات عينة الدر اسة لعبار ات بُعد التحفيز ، إذ بلغ المتوسط العام (3.17)

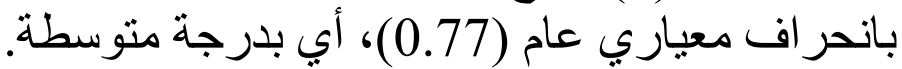

ثنانيا: بُعدالانتماء

الجدول (9) المتوسطات الحسابية والانحر افات المعيارية لفقر ات بُعد الانتماء، مرتبة تنازليا

\begin{tabular}{|c|c|c|c|c|c|}
\hline دالرضة & المعياري & الحستوسي & 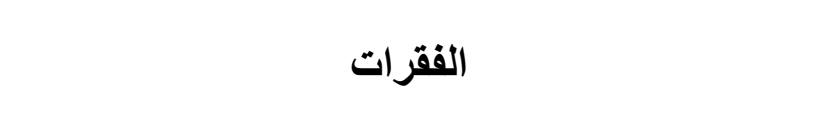 & قم & الرتبة \\
\hline 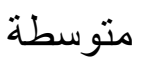 & 1.15 & 3.40 & أنشعر بالحماس تجاه عملي في معظم الأيام. & 6 & 1 \\
\hline 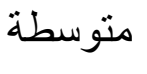 & 1.00 & 3.00 & تعزز وسائل الإعلام المختلفة مكانة المعلم في المجتمع. & 8 & 2 \\
\hline ضعيفة & 1.05 & 2.02 & أثشعر بالسعادة عند تدريسي للمنهج الذي أدرسه. & 7 & 3 \\
\hline 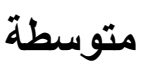 & 0.81 & 2.81 & المستوى العام & & \\
\hline
\end{tabular}

بيّنَ الجدول (9) نتائج تقدير ات عينة الدر اسة لعبار ات بُعد الانتماء، إذ بلغ المتوسط العام (2.81)

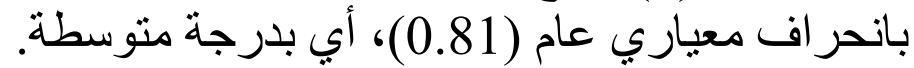

ثُالثًا: بُعدالعدالة

الجدول (10) المتوسطات الحسابية و الانحر افات المعيارية لفقر اتبُعدالعدالة، مرنبة تنازليا حسب لئب المتوسطات الحسابية 


\begin{tabular}{|c|c|c|c|c|c|}
\hline 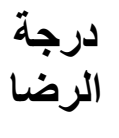 & 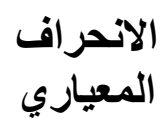 & 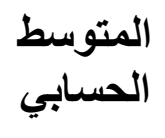 & الفقرات & قال & 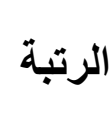 \\
\hline 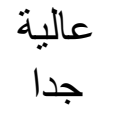 & 0.84 & 4.22 & للا يوجمين. معايير و اضحة لتحديد درجة الرضـا الوظيفي & 1 & 1 \\
\hline 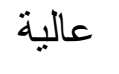 & 0.83 & 4.10 & أتمتع بعلاقة مع مديري في المدرسة & 11 & 2 \\
\hline 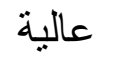 & 1.07 & 3.96 & أعتز بأنني أنتمي إلى مهنة التعليم & 10 & 3 \\
\hline 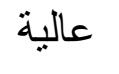 & 1.06 & 3.56 & بسعدني العمل في حياتي. & 12 & 4 \\
\hline 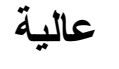 & 0.70 & 3.96 & المستوى العام & & \\
\hline
\end{tabular}

بيّنَ الجدول (10) نتائج تقدير ات عينة الدراسة لعبار ات بُعد العدالة، إذ بلغ المتوسط العام (3.96) بانحر اف معياري (10) (0.70)، أبي بدرجة اتبة عالية.

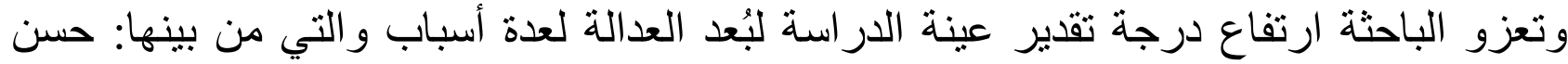

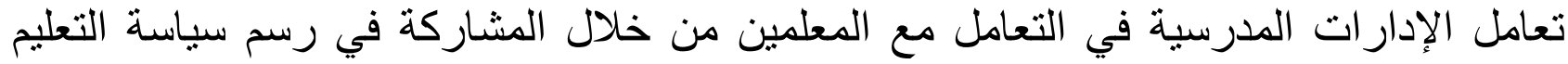

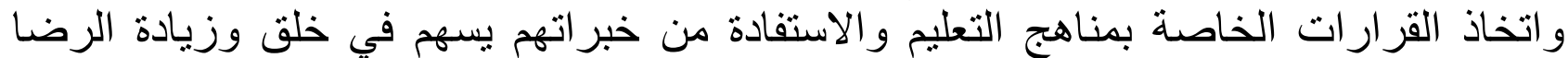

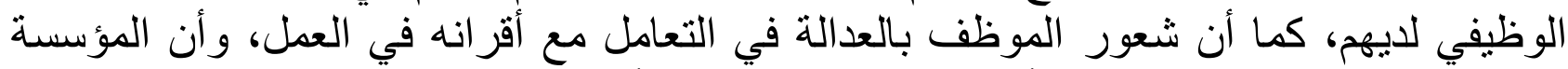
التي ينتمي إليها حريصة كما ان فلى مبدأ الموضور عية في تقييم الأداء.

ثالثا: مستوى الالتزام الوظيفي لئي

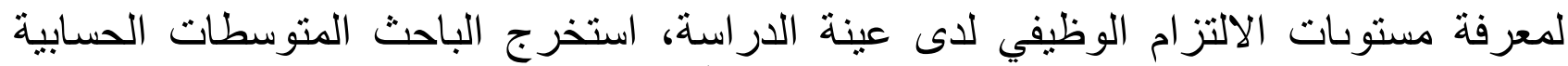
و الانحر افات المعيارية لتقدير ات عينة الدر اسة حسب أبعاد مقياس الالتز امالتنظيمي، و الجدول رات رقم (11) يوضح ذللك.

جدول (11) المتوسطات الحسابية والانحر افات المعيارية لأبعاد مقياس الالتز اما الوظيفي، مرنبة تناز ليا

\begin{tabular}{|c|c|c|c|c|c|}
\hline مستوى الالتزام & المعياري & الحستوسي & الأبعاد & 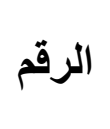 & الرتبة \\
\hline جالي & 0.67 & 4.22 & بُعد الحاجة للوظيفة & 3 & 1 \\
\hline عالي & 0.88 & 3.50 & بُعد الو لاء للوظيفة & 1 & 2 \\
\hline متوسط & 0.71 & 3.27 & بُعد المشكلات الحياتية & 4 & 3 \\
\hline متوسط & 0.68 & 3.21 & بُعد اخلاقيات الوظيفة & 2 & 4 \\
\hline
\end{tabular}




\begin{tabular}{|l|l|l|l|l|l|}
\hline عالي & 0.49 & 3.55 & مقياس الالتزام التنظيمي ككل & & \\
\hline
\end{tabular}

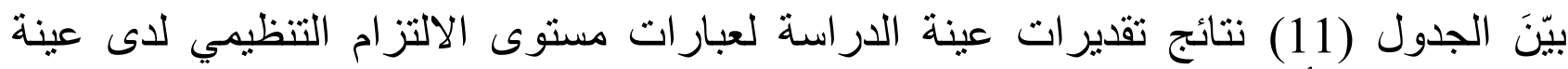

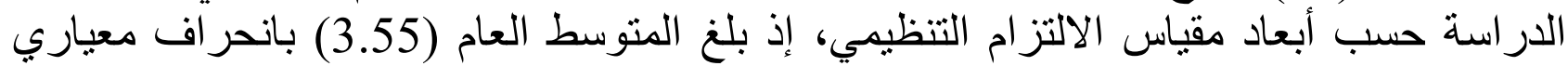

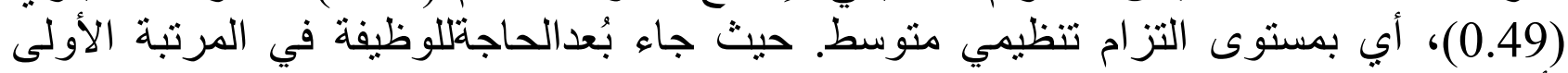

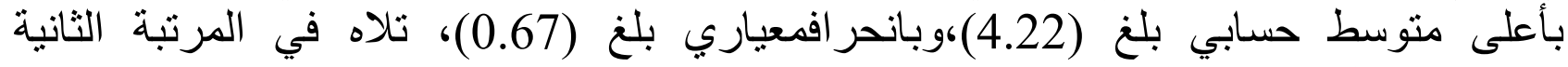

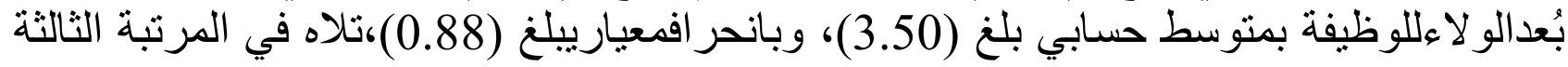

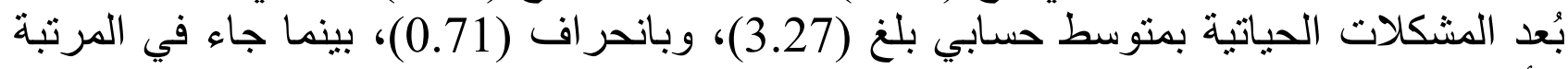
الأخيرة بُعد اخلاقيات الوظيفة بمتوسط حسابي بلغ لغن (3.21). النتائج حسب مستوى فقرات كل بُعد أولا: بُعد الولاء للوظيفة

الجدول (12) المتوسطات الحسابية و الانحر افات المعيارية لفقر اتبُعدالو لاءللوظيفة، مرتبة تتازليا

\begin{tabular}{|c|c|c|c|c|c|}
\hline 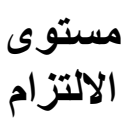 & 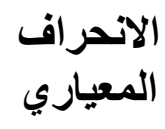 & المستبي & 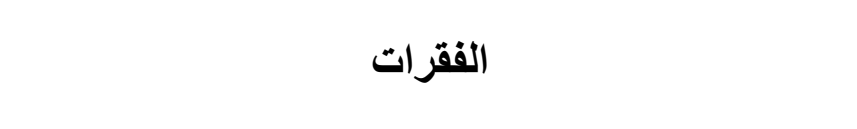 & 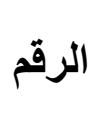 & 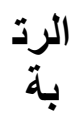 \\
\hline 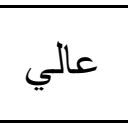 & 1.10 & 3.74 & لم أتلقي دورة تدريبية عن الالتز ام التنظيمي خلال فترة & 2 & 1 \\
\hline متوسط & 1.07 & 3.65 & جيد. أنتعر بعدم الالتز ام لوظيفتي عندما يكون أدائسي غير & 3 & 2 \\
\hline متوسط & 1.01 & 3.56 & مبدأ الالتز ام التنظيمي غير و اضح لدى المعلمين. & 1 & 3 \\
\hline متوسط & 1.07 & 3.39 & أفضل الخدمة في مدرستي على المدارس الأخرى. & 10 & 4 \\
\hline 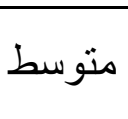 & 1.18 & 3.15 & 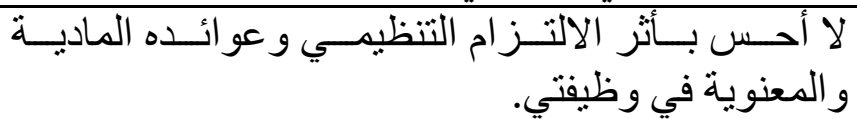 & 4 & 5 \\
\hline عالي & 0.88 & 3.50 & المستوى العام & & \\
\hline
\end{tabular}

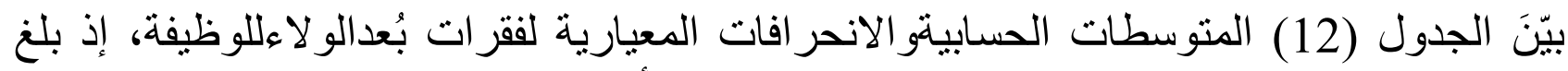

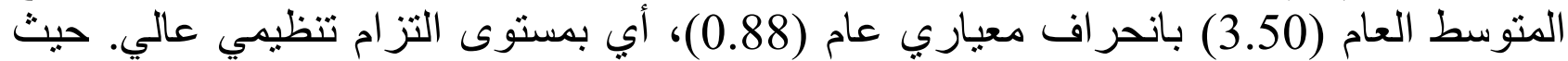

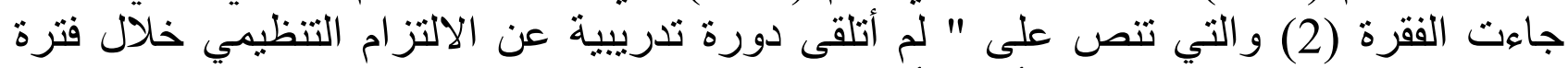

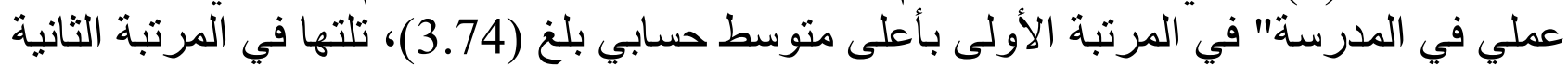

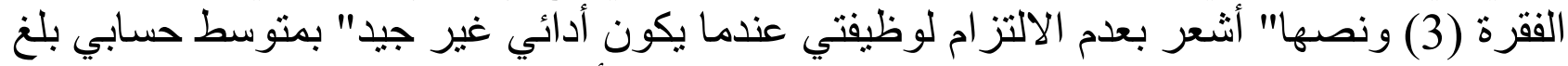

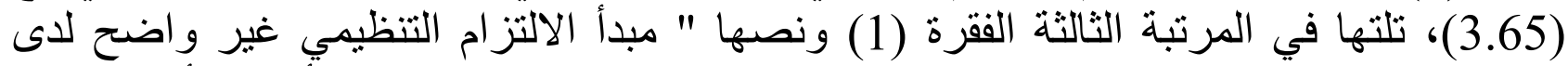

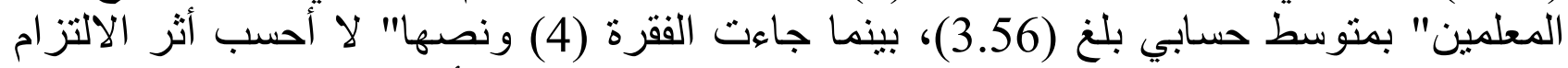

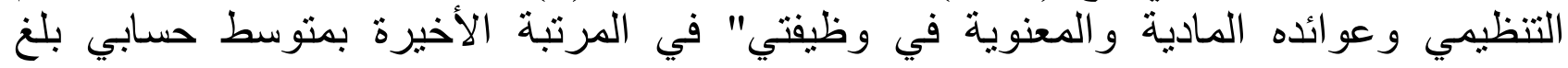


ثانيا: بُعد اخلاقيات الوظيفة

الجدول (13) المتوسطات الحسابية و الانحر افات المعيارية لفقر ات بُعد اخلاقيات الوظيفة مرتبة تنازليا

\begin{tabular}{|c|c|c|c|c|c|}
\hline الالتزام & 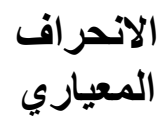 & المستوسط & الفقرات & 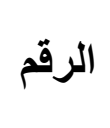 & 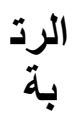 \\
\hline عالي ل & 0.93 & 3.72 & لا تفرق الوزارة بين الو لاء الايجابي و الو لاء السلبي في & 6 & 1 \\
\hline متوسط & 1.10 & 3.11 & يتساوى الو لاء الايجابي و السلبي لدى المعلمين في & 5 & 2 \\
\hline متوسط & 1.15 & 2.80 & أحضر فعاليات المدرسة. & 13 & 3 \\
\hline متوسط & 0.68 & 3.21 & المستوى العام & & \\
\hline
\end{tabular}

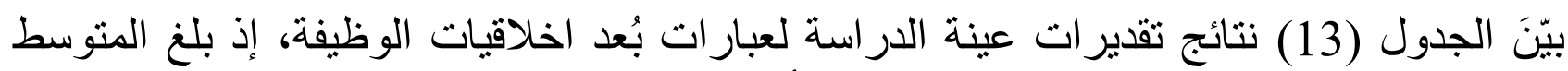

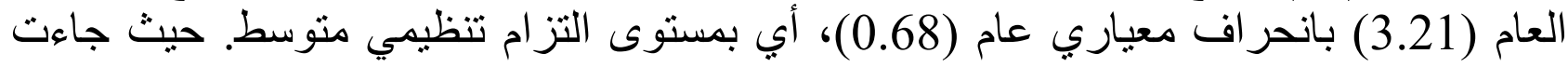

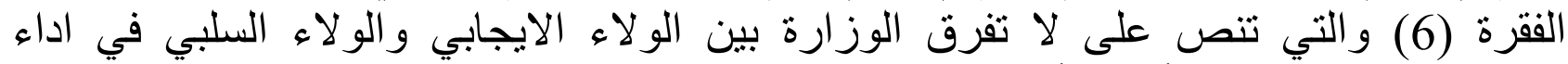

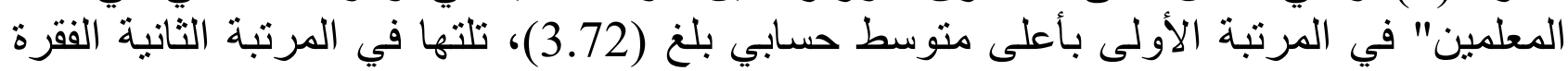

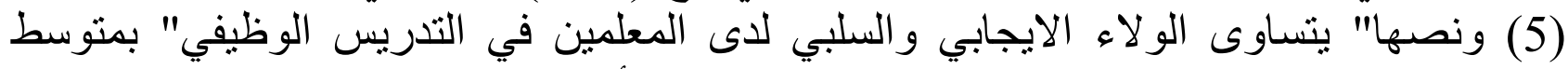

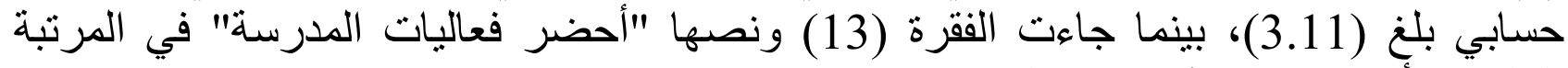
الثالثة و الأخيرة بمتوسط حسابي بلغ (3.11)، بلناءن (2.80).

ثالثا: بُعد الحاجة للوظيفة

جدول (14) المتوسطات الحسابية والانحر افات المعيارية لفقر اتبُعدالحاجةلللوظيفة، مرتبة تناز ليا

\begin{tabular}{|c|c|c|c|c|c|}
\hline مستتوى & المعياري الاتحر & الحستبي & الفقرات & قر & 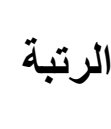 \\
\hline جدالي & 0.74 & 4.50 & اتعاون مع زملائي في مدرستي. & 8 & 1 \\
\hline 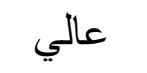 & 0.93 & 4.15 & استلم التعليمات بقلب مسرور. & 9 & 2 \\
\hline 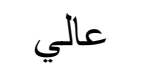 & 0.85 & 4.01 & أجتهد في سبيل انجاح مدرستي. & 7 & 3 \\
\hline جالي & 0.67 & 4.22 & المستوى العام & & \\
\hline
\end{tabular}

بيّنَ الجدول (14) نتائج تقديرات عينة الدر اسة لعبار ات بُعد الحاجة للوظيفة، إذ بلغ المتوسط العام 


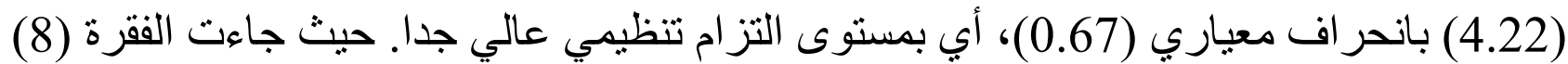

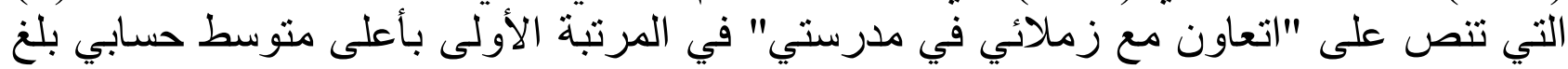

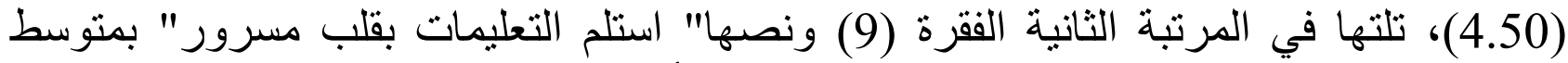

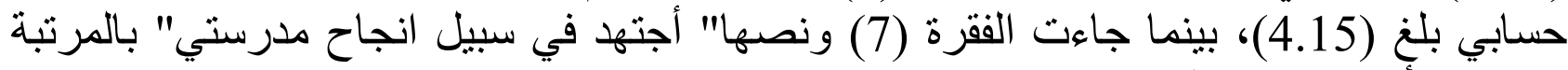

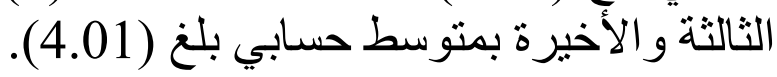
رابعا: بُعد المشكلات الحياتية

جدول (15) المتوسطات الحسابية والانحر افات المعيارية لفقر ات بُعد المشكلات الحياتية، مرتبة تنازليا

\begin{tabular}{|c|c|c|c|c|c|}
\hline مستوى & المعياري & الحسابي & الفقرات & 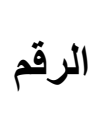 & بة \\
\hline 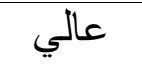 & 1.11 & 3.62 & أصل مبكر ا إلى العمل. & 12 & 1 \\
\hline عالي & 1.02 & 3.54 & ألجدرســـــــولة فـــ التعامـل مـع سياســات & 11 & 2 \\
\hline متوسط & 1.35 & 2.66 & أضيف وقتا للددرسة عند الحاجة. & 14 & 3 \\
\hline منوسط & 0.71 & 3.27 & المستوى العام & & \\
\hline
\end{tabular}

بيّنَ الجدول (15) نتائج تقدير ات عينة الدراسة لعبار ات بُعد المشكلات الحياتية، إذْ جاء معدل هذا

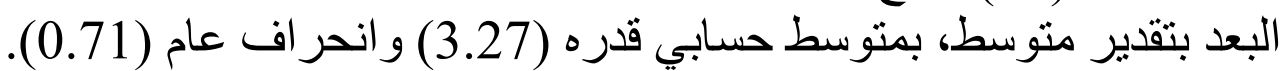

أ. جاءت نتائج الدراسة مشيرة إلى أن درجة تقدير عينة الدراسة للمتغيرات الثثلاثة: تصميم

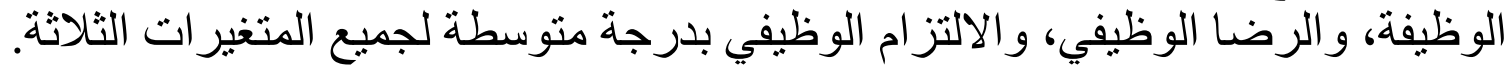

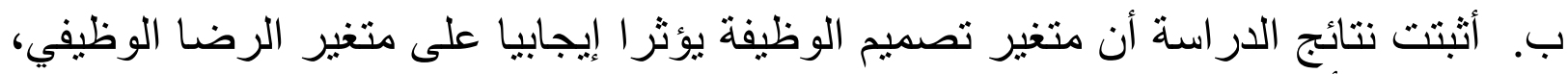

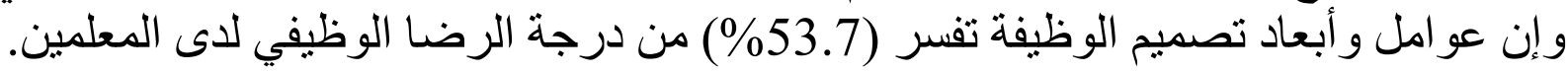

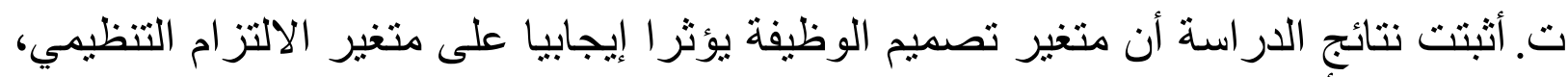
و إن عو امل وأبعاد تصميم الوظيفة مجتمعة تفسر (22.6\%) من درجة الالتز ام التنظيمي لدى التى التئ المعلمين.

التوصيات:

أ. تفعيل وممارسة مؤشرات حرية الأداء من قبل المعلمين والمعلمات كعامل وظيفي أساسي مؤثر في الرضار و الالتز ام التنظيمي.

ب. ضرورة وضع أسس صحيحة لنظام الترقيات من أجل تعزيز الرضا و الو لاء الوظيفي.

قائمة المصادر والمراجع

أبو النصر ، مدحت. 2009. التخطيط للمستقبل في المنظمات الذكية. القاهرة: المجموعة العربية للتدرب و النشر. 
الرو اس، منى بنت عبد السلام. 2013. الرضا الوظيفي لدى معلمي مدارس التعليم ما بعد الأساسي ماسي بو لاية صلالة من وجهة نظر هم. (رسالة ماجستير غير منشورة). جامعة ظفار ، صلالة. الكساسبة، حمح مفضي، و آخرون. 2009. "تأثير ثقافة التمكين و القيادة التحويلية على المنظمة المتعلمة". المجلة الأردنية في إدارة الأعمال، الأردن.

الجامودي، سعيد بن سالم. 2016. المدرسة العمانية كمنظمة متعلمة المؤر خ مقترح. (رسالة دكتور اه غير منشورة)، جامعة العلوم الاسلامية الماليزية.

آل مكي، عو اطف إبر اهيم. 2011. المشكلات الإدارية في مكاتب الإشر اف التربوي ومو اجهتها

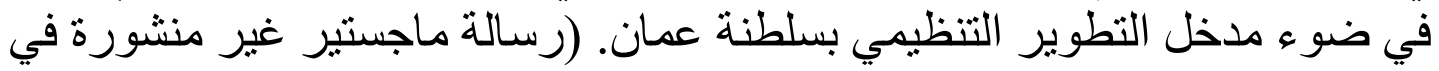

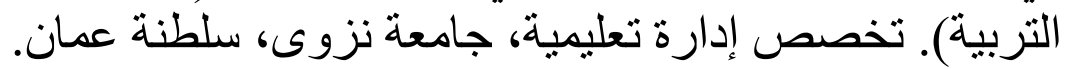

المنذري، إبر اهيم بن ححم. 2013. المشكلات التي تو اجهها الإدارة المدرسية في سلطنة عمان. (رسالة ماجستير غير منشورة)، جامعة اليزموك، الئه الأردن.

صلاح، فلاح كريم. 2014. "تأثير إعادة تصميم الوظيفة في الأداء المنظمي. بحث ميداني لعينة

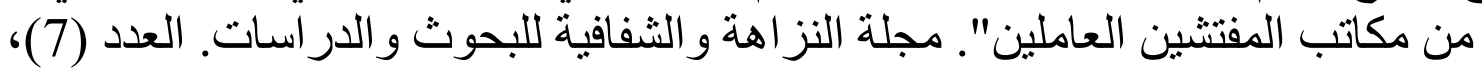
وزارة الثباب ون مالب الرياضة.

عطاري، عارف. 2006. "الو لاء التنظيمي للهيئة الإدارية و التدريسية بمدارس وزارة التربية

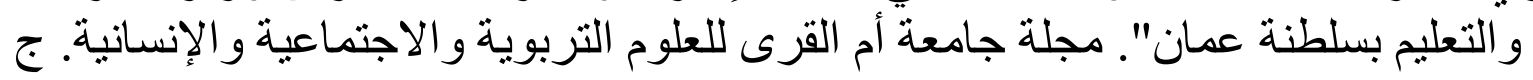
$.82-13.2 \varepsilon .18$ وزارة التربية و التعليم. 2016. دليل الإحصساء السنوي. وزارة التربية و التعليم. 1998. دليل عمل مدارس التعليم الأساسي. مسقط. وزارة التربية والتعليم. 2006. دليل نظام تطوير الأداء المدرسي. مسقط. وزارة التربية و التعليم. 2016. تقرير تقييم المدراس الثانوية، 2005. المديرية العامة للتربية والتعليم شمال الباطنة 2014.

\section{ARABIC REFERENCES IN ROMAN ALPHABET}

'Abu Alnasr, Madhat. 2009. Altakhtit Lilmustaqbal Fi Almunazamat Aldhakiati. Alqahrt: Almajmueat Alearabiat Liltadarub Walnashr.

Alrawas, Munaa Bnt Eabd Alsalam. 2013. Alrada Alwazifia Ladaa Maelami Madaris Altaelim Ma Baed Al'asasii Biwilayat Salalat Min Wijhat Nazarhum. (Rsaalat Majstayr Ghyr Minshurta). Jamieat Zufari, Salalat.

Alkusasibat, Muhamad Mafadi, Wakharawun. 2009. "T'athir Thaqafat Altamkin Walqiadat Altahwiliat Ealaa Almunazamat Almutaealimata". Almajalat Al'urduniyat Fi 'lidarat Al'aemali, Al'urdunn.

Aljamudi, Saeid Bin Salim. 2016. Almadrasat Aleumaniat Kamunazamat Mutaealimat Almuarikh Muqtaraha. (Rsalat Dukturah Ghyr Minshurta). Jamieat Aleulum Al'iislamiat Almaliziat.

Al Mikya, Euatif 'librahim. 2011. Almushkilat Al'iidariat Fi Makatib Al'iishraf Altarbuii Wamuajahatiha Fi Daw' Madkhal Altatwir Altanzimii Bisiltanat Euman. (Rsalat Majstayr Ghyr Manshurat Fi Altrby). Tukhasas 'lidaratan Taelimiat, Jamieatan Nazwaa, Saltanat Eaman.

almandhari, 'iibrahim bin mahmid. 2013. almushkilat alty tuajihuha al'iidarat almadrasiat fi saltanat eumaana. (rsalat majstayr ghyr minshurta). jamieat alyarmuk. al'urdunn. 
slah, filah krim. 2014. "t'athir 'iieadat tasmim alwazifat fi al'ada' almunazmi. bahathi midaniin lieayinat min makatib almufatishin aleamalina". majalat alnazahat walshaffafiat lilbihawth waldirasati. aleadad (7), wizarat alshabab walriyadat.

eatari, earuf. 2006. "alwala' altanzimii lilhayyat al'iidariat waltadrisiat bimadaris wizarat altarbiat waltaelim bisiltanat eamaana". majalat jamieat 'am alquraa lileulum altarbawiat walaijtimaeiat wal'iinsaniat. j 18. ea2. 13-82.

wizarat altarbiat waltaelim. 2016. dalil al'iihsa' alsnwy.

wizarat altarbiat waltaelim. 1998. dalil eamal madaris altaelim al'asasi. masqat.

wizarat altarbiat waltaelim. 2006. dalil nizam tatwir al'ada' almadrasii. masqat.

wizarat altarbiat waltaelim. 2016. taqrir taqyim almidras althaanwiat, 2005.

almadiriat aleamat liltarbiat waltaelim shamal albatinat 2014.

\section{REFERENCE LIST}

Agnihotri, A. 2013. “Job Satisfaction among School Teachers”. Indian Streams Research Journal, 32 , PP 17 .

Chi, Hsingkuang \& Yeh, Hueryren. 2013. "The Organizational commitment, Personality traits and teaching efficacy of junior high school teachers: The Meditating effect of job involvement”. The Journal of Human Resource and Adult Learning. 9, 2, 131- 142

Tasinm, S. 2006. Job Satisfaction among Female Teachers: A study on Primary Schools in Bangladesh. (Unpublished Med thesis), University, Norway . 